\title{
FRP Strengthened Brick-Infilled RC Frames: An Approach for their Proper Consideration in Design
}

\author{
Constantine C. Spyrakos ${ }^{*}{ }^{1}$, Charilaos A. Maniatakis ${ }^{1}$, Eleni Smyrou ${ }^{2}$ and Ioannis N. Psycharis ${ }^{1}$ \\ ${ }^{1}$ Laboratory for Earthquake Engineering, School of Civil Engineering, National Technical University of Athens, Greece; ${ }^{2}$ Soil \\ Mechanics Laboratory, School of Civil Engineering, National Technical University of Athens, Greece
}

\begin{abstract}
A considerable number of existing buildings in seismic prone countries has been constructed either based on earlier concepts for seismic design or without applying seismic provisions. As a consequence, their seismic upgrade is a matter of concern. In urban environments, these structures usually consist of reinforced concrete (RC) frames with brick infill walls. Their strengthening with traditional methodologies, such as concrete jackets and shear wall construction, often results in operation interruption and high cost. The present research examines the complex response of RC frames and brick infill walls strengthened with Fibre Reinforced Polymers (FRP), a recently proposed retrofit scheme that becomes attractive because of its low cost and ease of implementation. Instead of the commonly used pair of compression struts that models the infill wall, a multiple strut masonry panel element model with advanced constitutive laws is applied for the representation of the nonlinear response of the infill wall, while a tension tie is used to consider the FRP sheets contribution on the response. The parameters of the wall and the FRP elements that are used in the numerical model are calibrated against experimental results available in the literature for two-storey, one-bay reinforced concrete frames subjected to cyclic loading. The effectiveness of this innovative technique is presented considering the response of the masonry infilled RC frame with and without retrofit. By comparison of the results, conclusions are drawn concerning design procedures.
\end{abstract}

Keywords: FRP composites, infill walls, masonry, reinforced concrete frames, retrofit, seismic design, structural enhancement.

\section{INTRODUCTION}

A large number of reinforced concrete (RC) structures were severely damaged or even collapsed during recent earthquakes in Greece and worldwide. Recent earthquakes in Greece and Turkey revealed that many existing structures in seismically active regions do not have sufficient strength, stiffness, and/or ductility capacity to withstand even moderate seismic loads. These structural shortcomings became apparent especially after recent large earthquakes, i.e., Athens 1999, Kocaeli 1999 and Bingol 2003. As recently revealed by the Census of Building Wealth in Greece [1], $80 \%$ of the buildings that are currently in service were constructed before 1985, without the application of modern concepts for seismic design. These buildings often present common weaknesses attributed to their design or construction that explain their high seismic vulnerability, i.e., existence of soft first or intermediate storey, application of strong-beam and weak-column design approach, use of low strength concrete and lack of adequate reinforcement detailing. The present research studies the efficiency of upgrading existing masonry-infilled RC frame structures with the use of Carbon Fibre Reinforced Polymers (CFRP).

Various methodologies have been proposed for strengthening and seismic upgrading existing structures, such as

\footnotetext{
* Address correspondence to this author at the Laboratory for Earthquake Engineering (L.E.E.), School of Civil Engineering, Department of Structural Engineering, National Technical University of Athens, Zografos, Athens, 15700, Greece; Tel; +30 2107721187, Fax; +30 2107721182.

E-mail: cspyrakos@central.ntua.gr
}

construction of new reinforced concrete shear walls, precast elements or steel diagonal struts and the use of RC jackets. These methods, even though widely accepted and efficiently implemented in many cases, result in significant increase in mass and stiffness and therefore provoke critical changes in the design seismic loads. Moreover, they require extensive interventions, aesthetical modifications, significant cost or even operational interruptions for their proper implementation. On the other hand, analyses show that CFRP can effectively be used to strengthen masonry-infilled RC frame structures [2].

During the last two decades, the use of polymers reinforced with carbon fibres has been an effective alternative to ameliorate structural vulnerability [3, 4]. The fibre reinforced polymers are characterized by small thickness and weight, relative ease of application, resistance to environmental conditions and high strength compared to conventional materials. Their application results in significant increase in strength with very little modification of mass and stiffness; thus, slightly modifying the design seismic loads that are expected for the retrofitted structure.

Reinforced concrete frame structures with brick infill walls are common in urban areas. Infills have been usually considered as dead loads for the structural design, despite the fact that significantly affect the strength and stiffness of the RC frames to which they are attached. This is partly attributed to the lack of ductile behaviour, their complex dynamic behaviour, the lack of sufficient experimental data, and the difficulty in modelling many of the failure modes because of 
the interaction of masonry with the frame members. Some representative types of failure are the following: (a) detach of the walls at their base and failure of columns also at their base; (b) horizontal cracking of masonry, usually at midheight, if its shear strength is exceeded, and yield or shear failure of columns at the same height; (c) diagonal cracking of the wall followed by plastic hinge formation at the ends of the columns; (d) fracture of the masonry at their corners due to excessive compression. Under cyclic loading, all the four corners of the masonry wall may present fracture and plastic hinges can be formed in various parts of the columns and the beams of the frame [5].

Under small lateral loading, the RC frame and the infill masonry operate uniformly as a single body. As the lateral loads increase, differences are observed between the RC frame and wall deformations and the complex behaviour becomes highly non-linear. The interaction between frame and masonry significantly increases the lateral stiffness of the system and drastically alters the design response to dynamic loads [6]. The infill walls, because of their brittle failure which is characterized by rapid strength and stiffness degradation, perform in a very complex mode under dynamic loading [6]. The contribution of infill walls to lateral stiffness depends on the type of loading and is drastically reduced under reversed cycling loading [7]. In engineering practice, infill walls are usually modelled as a combination of diagonal struts following a macro-modelling approach [810] without significant loss of accuracy. However, more complex models, such as finite element models with a micromodelling approach, with the use of constitutive relations available in the literature should be implemented to account for the non-linearity of the response of infilled RC frames, the accurate detection of possible failure modes and the verification of simplified models considering the effects of several critical factors, including the width-to-the-height of the infilled frame ratio and friction mechanism at the interface between the frame and the infill [11-18]. In such models, openings can also be considered, the location and dimensions of which significantly affect the stiffness and the strength characteristics of the infills $[13,19,20]$.

With the increase of lateral loads in an infilled RC frame with no openings, the orbits of compressive and tensile stresses follow the two diagonal paths. Therefore, the wall behaves as a strut in the diagonal that is under compression, while detachment from the surrounding frame is observed at the other diagonal. The placement of CFRP along the two main diagonals of the wall allows the wall to undertake tensile stresses along the tensile diagonal, limiting deformation of the frame and increasing the resistance to lateral loads [21-23]. Several efforts have been made recently to understand the in- and out-of-plane behaviour of FRP infilled RC frames [3, 21-25] that resulted in the identification of two main failure modes for this retrofit method: (a) anchor failure; and (b) debonding. The first failure mode occurs at relatively small strains, when FRP anchors of small length are used. After the anchor failure occurs, the strains increase rapidly resulting in rupture of the masonry in compression at the corners of the diagonal. The second failure mode occurs at greater strains and starts with the detachment of FRP sheets from the masonry surface. Horizontal cracks are then developed resulting in shear failure.
Since widespread dispersion in the mechanical characteristics of masonry is observed, as possible accurate knowledge on these values should be considered as a prerequisite for the effective application of this retrofit scheme. The flat jack test is a relatively simple method which could be used for in-situ measurement of the basic mechanical properties of masonry [26, 27].

The present research attempts to validate analytically the effectiveness of the FRP application on brick infilled RC frames using the experimental results of Akgüzel [28] and Özden \& Akgüzel [25]. The nonlinear response of the brick infill wall is modelled applying the four node masonry panel element developed by Crisafulli [9], available in SeismoStruct [29], a fibre-based finite element software package for static and dynamic analyses, that takes into account both geometric and material nonlinearities.

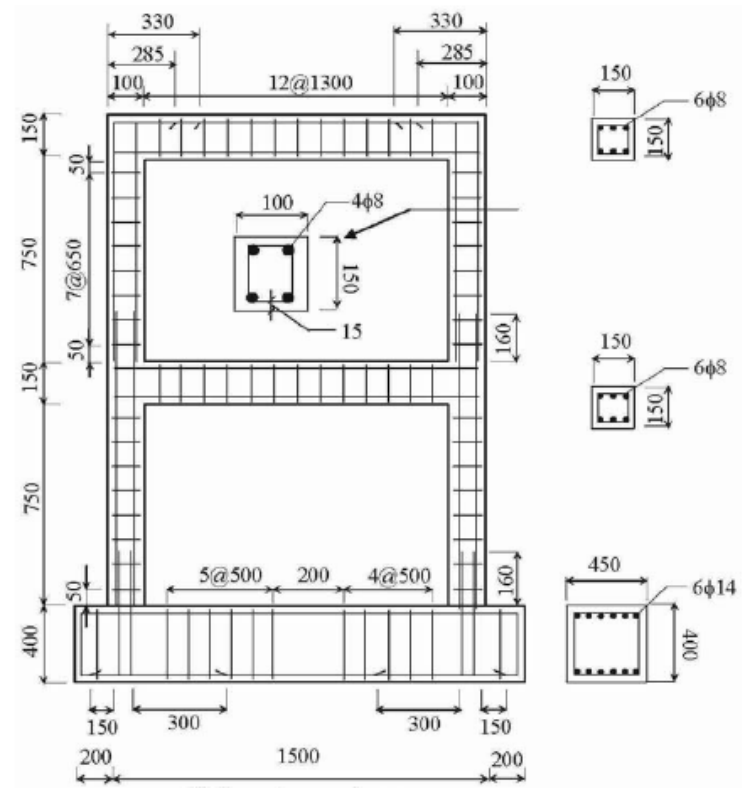

Fig. (1). Bare frame $U_{1}$ tested in the Boğaziçi University, Structures Laboratory (dimensions in $\mathrm{mm}$ ) - reproduced from [28].

\section{DESCRIPTION OF SPECIMENS AND LOADING}

The research of Akgüzel [28] includes experiments on five identical two-storey scaled frames named $U_{i}(i=1,2, \ldots$, 5 ), that exhibit common, for existing RC structures, structural shortcomings, i.e., lack of sufficient anchorage length of the longitudinal reinforcement, low concrete strength, insufficient column lap splice length and poor confinement: (1) $U_{1}$ frame was a bare frame without infills; (2) $U_{2}$ frame was identical to $U_{1}$ with brick-infills without FRP strengthening; (3) $U_{3}$ frame was identical to $U_{2}$ with CFRP sheets of inadequate bond length along the two main diagonals on both stories; (4) $U_{4}$ frame was identical to $U_{3}$ with rather sufficient bond length on the masonry surface; (5) $U_{5}$ frame was identical to $U_{3}$ and $U_{4}$ but the appropriate anchorage of the FRPs was achieved by extending the sheets outside the diagonals of the infills on the columns of the frame. All the experiments were conducted in the Structures Laboratory of Boğaziçi University. Only the first three frames $U_{1}, U_{2}$ and $U_{3}$ are considered in the present research. 

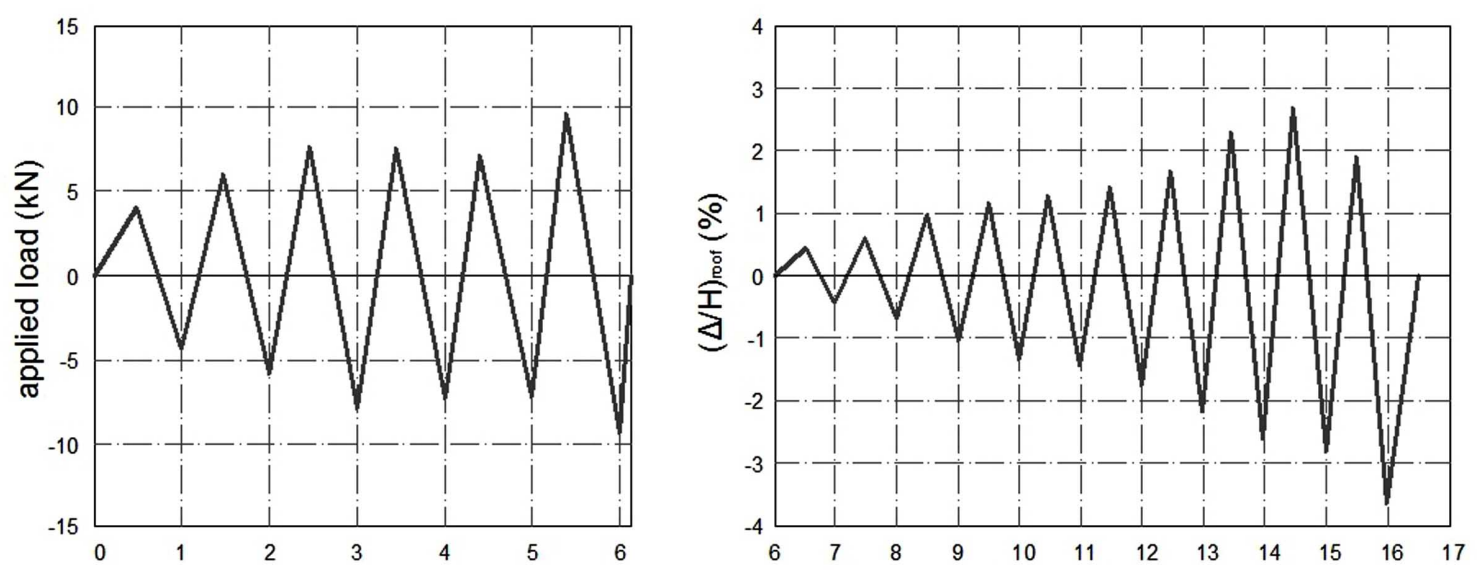

Cycle No.

Fig. (2). Loading history for cyclic analysis of the bare frame $U_{I}$ [28].

The two-storey, one-bay plane frames with a $0.90 \mathrm{~m}$ typical storey height and $1.50 \mathrm{~m}$ typical bay length are shown in Fig. (1). Orthogonal sections of $100 \mathrm{~mm} \times 150 \mathrm{~mm}$ and $150 \mathrm{~mm} \times 150 \mathrm{~mm}$ were used for the columns and the beams, respectively, as shown in Fig. (1), with the small dimension of the columns' section being in-plane with the frame. The compressive strength of the concrete was slightly varying between the frames, with an average value of $f_{c}=$ 15.4 MPa. Typical longitudinal reinforcement of $4 \varnothing 8$ and $6 \varnothing 8$, with yield strength $f_{y}=380 \mathrm{MPa}$, was used for the columns and the beams, respectively. Transverse reinforcement of $\varnothing 4 / 100 \mathrm{~mm}$, with yield strength $f_{w y}=241 \mathrm{MPa}$, was used for the columns and the beams. An insufficient lap splice length of $160 \mathrm{~mm}$ was provided at each storey base. The concrete cover was $15 \mathrm{~mm}$. For more information on the material properties one should refer to [25, 28].

Bricks with dimensions $70 \mathrm{~mm}$ (height, put in the vertical direction), $90 \mathrm{~mm}$ (width) and $85 \mathrm{~mm}$ (length) were used for the construction of infill walls in frames $U_{2}$ to $U_{5}$. The bricks had six $25 \mathrm{~mm} \times 25 \mathrm{~mm}$ orthogonal holes along the $70 \mathrm{~mm} \times$ $85 \mathrm{~mm}$ section. Low strength mortar was used between the brick connection and for the plaster. The CFRP sheets were applied at both sides of the masonry using epoxy resin. In all specimens, the material was applied in layers of $200 \mathrm{~mm}$, in such a way that could operate along the two main diagonals of the wall. The tensile strength and the modulus of elasticity of the fibres were $f_{f i b}=3500 \mathrm{MPa}$ and $E_{f i b}=230000 \mathrm{MPa}$, respectively. The tensile strength and the modulus of elasticity of the epoxy were $f_{m}=30 \mathrm{MPa}$ and $E_{m}=3800 \mathrm{MPa}$, respectively.

Cyclic loading was applied to the specimens in two phases; firstly, the frames were pushed under lateral cyclic forces with a triangular pattern along their height, until the first yield occurred; then, a cyclic loading phase was following till failure. The loading history for $U_{1}$ frame is shown in Fig. (2). The loading was applied at the beam of the second floor only, while for the other frames the loading was applied at both floors, with the load of the first floor being half in magnitude compared to the load of the second floor. On the columns, $30 \mathrm{kN}$ axial compressive load was applied. The number of cycles and the amplitude of the loading were dif- ferent for each specimen, since yield and failure occurred at different levels of force and deformation [25, 28].

\section{MODELING OF THE SPECIMENS}

As mentioned, three types of RC frames were studied: the bare frame $U_{1}$ and two infilled frames, the unstrengthened frame $U_{2}$ and the CFRP strengthened frame $U_{3}$. The numerical models for the bare frame and the infilled ones had the same geometry with the typical section details shown in Fig (1). The frame structure was modelled using inelastic fibre elements for the beams and the columns, which were calibrated from the experiments [28]. The load versus deformation response of a fibre model depends on the uniaxial stress-strain relations of the materials, specifically the concrete and the reinforcement. The flexural stiffness can be expressed accurately by the specified material relations and varies depending on the level of the axial load. The damage distribution is estimated from the spread of inelasticity along the member length and across the section depth. The RC frames consisted of concrete columns and beams, each one of which was meshed in four elements, according to the displacement-based element concept for the estimation of the element curvature [30]. The steel model proposed by Menegotto and Pinto [31, 32] and the nonlinear constant confinement concrete model of Mander et al. [33] were applied for the reinforcement bars and the concrete, respectively. The former can be applied even for smooth reinforcing bars, i.e., without ribs, with a proper selection of parameters [34].

The masonry panel element model used in the present study was originally developed by Crisafulli [9] and calibrated by Smyrou [19], to simulate the nonlinear response of masonry in frame structures [10]. Each panel element contained six elements: two struts parallel to each diagonal that transferred the axial load between the two diagonal nodes and a pair of springs related to each diagonal (one for each direction of loading) that transferred the shear load from the top of the wall to the base. Each one of the latter was activated if the corresponding diagonal at which it belonged was compressed; thus its activation was directly dependent on the deformation level of the masonry. 
Table 1. Main Model Parameters

\begin{tabular}{|c|c|c|c|c|}
\hline Model & Parameter name & $\begin{array}{c}\text { Default value in } \\
\text { Seismostruct }\end{array}$ & Common range of values & Selected value \\
\hline \multirow{3}{*}{$\begin{array}{c}\text { Concrete } \\
\text { model - Man- } \\
\text { der } \text { et al. } \text { [33] }\end{array}$} & Compressive strength $-f_{c}$ & $30.0 \mathrm{MPa}$ & $15 \sim 45 \mathrm{MPa}$ & $15.4 \mathrm{MPa}$ \\
\hline & Tensile strength $-f_{t c}$ & $0.0 \mathrm{MPa}$ & $0.50 \sim 0.75 \mathrm{MPa}$ & $0.0 \mathrm{MPa}$ \\
\hline & Strain at peak stress $-\varepsilon_{c}$ & $0.002 \mathrm{~mm} / \mathrm{mm}$ & $0.002 \sim 0.0022 \mathrm{~mm} / \mathrm{mm}$ & $0.002 \mathrm{~mm} / \mathrm{mm}$ \\
\hline \multirow{4}{*}{$\begin{array}{l}\text { Steel model - } \\
\text { Menegotto \& } \\
\text { Pinto }[31,32]\end{array}$} & Yield strength $-f_{y}$ & $500 \mathrm{MPa}$ & $230 \sim 650 \mathrm{MPa}$ & $200 \mathrm{MPa}$ \\
\hline & Strain hardening parameter $-\mu_{s}$ & 0.005 & $0.005 \sim 0.015$ & 0.005 \\
\hline & Transition curve initial shape parameter - $R_{0}$ & 20.0 & & 19.0 \\
\hline & $\begin{array}{l}\text { Transition curve shape calibrating coefficient - } \\
\qquad a_{l}\end{array}$ & 18.5 & & 18.7 \\
\hline \multirow{10}{*}{$\begin{array}{c}\text { Masonry } \\
\text { Panel Model - } \\
\text { Crisafulli [9] }\end{array}$} & Initial Young modulus - $E_{\text {mas }}$ & $1.6 \mathrm{GPa}$ & & $1.7 \mathrm{GPa}$ \\
\hline & Compressive strength $-f_{\text {mas }}$ & $1 \mathrm{MPa}$ & & $1.65 \mathrm{MPa}$ \\
\hline & Tensile strength $-f_{t, \text { mas }}$ & $0.575 \mathrm{MPa}$ & & $0.575 \mathrm{MPa}$ \\
\hline & Strut Area $2-A_{2}$ & $40 \%$ & & $15 \%$ \\
\hline & Strain at maximum stress $-e_{m, \text { mas }}$ & $0.0012 \mathrm{~mm} / \mathrm{mm}$ & $0.001 \sim 0.005 \mathrm{~mm} / \mathrm{mm}$ & $0.0014 \mathrm{~mm} / \mathrm{mm}$ \\
\hline & Utimate strain $-e_{u, \text { mas }}$ & $0.024 \mathrm{~mm} / \mathrm{mm}$ & & $0.012 \mathrm{~mm} / \mathrm{mm}$ \\
\hline & Closing strain $-e_{c l, \text { mas }}$ & $0.003 \mathrm{~mm} / \mathrm{mm}$ & $0 \sim 0.003 \mathrm{~mm} / \mathrm{mm}$ & $0.003 \mathrm{~mm} / \mathrm{mm}$ \\
\hline & Starting unloading stiffness factor $-\gamma_{u n}$ & 1.5 & $1.5 \sim 2.5$ & 1.5 \\
\hline & Strain reloading factor $-\alpha_{c h}$ & 0.2 & $0.2 \sim 0.4$ & 0.2 \\
\hline & Plastic unloading stiffness factor $-e_{x l}$ & 3.0 & $2.0 \sim 3.0$ & 3.0 \\
\hline \multirow{3}{*}{$\begin{array}{l}\text { Trilinear } \\
\text { CFRP model }\end{array}$} & Tensile strength - $f_{t}$ & $3000 \mathrm{MPa}$ & $1900 \sim 4800 \mathrm{MPa}$ & $953 \mathrm{MPa}$ \\
\hline & Initial stiffness - $E_{l}$ & $300 \mathrm{GPa}$ & $70 \sim 700 \mathrm{GPa}$ & $130 \mathrm{GPa}$ \\
\hline & Post-peak stiffness - $E_{2}$ & $500 \mathrm{GPa}$ & & $130 \mathrm{GPa}$ \\
\hline
\end{tabular}

A simple uniaxial tri-linear model that acts only under tension was used to simulate the CFRP. The main parameters that determine the response of this element are: (i) the tensile strength; $f_{t}$, (ii) the initial stiffness; $E_{1}$, (iii) the post- peak stiffness, $E_{2}$; and (iv) the specific weight, $\gamma$. The main parameters needed to describe the constitutive laws of the models implied are shown in Table 1. The selected values result from either the characteristics of the materials used for the specimens construction [28] or the parametric analyses that follow. The range of values and the default values described in Table 1 are indicative and are based on the literature included in the development of the Seismostruct code
[29]. When a value is not included in the "common range of values" column, either the range is extremely wide or there are insufficient experimental data to determine a reasonable range for this parameter. In several cases the parameter is calculated analytically, so the determination of a strict range is of no point. In the following a brief discussion on these main parameters is made.

\subsection{Concrete Model}

The constitutive relationship proposed by Mander et al. [33] and the cylic rules proposed by Martinez-Rueda and 
Elnashai [35] were used to model the concrete behavior. The confinement effects are considered in the model while the confined stress $f_{c c}$ and ultimate strain $e_{c c}$ are calculated based on the compressive strength $f_{c}$, the strain at peak stress $\varepsilon_{c}$ of the unconfined concrete and the lateral reinforcement. The following equations are used to calculate the stress-strain relationships:

$$
\begin{aligned}
& f_{c c}=f_{c} \cdot\left[2.254 \cdot \sqrt{1+\frac{7.94 f_{l p}}{f_{c}}}-\frac{2 f_{l p}}{f_{c}}-1.254\right] \ldots \\
& \varepsilon_{c c}=\varepsilon_{c} \cdot\left[5 \cdot\left(\frac{f_{c c}}{f_{c}}-1\right)+1\right] \ldots \\
& x=\frac{\text { strain }}{\varepsilon_{c c}}, \quad E_{\mathrm{sec}}=\frac{f_{c c}}{\varepsilon_{c c}}, \quad E_{c}=5000 \sqrt{f_{c}}, \quad r=\frac{E_{c}}{E_{c}-E_{\mathrm{sec}}}, \quad \text { stress }=\frac{f_{c c} \cdot x \cdot r}{r-1+x^{r}}
\end{aligned}
$$

where:

$f_{l p}$ is the confining pressure of concrete which is calculated based on confinement reinforcement and geometric characteristics and is assumed to be constant for the entire stress-strain range in Seismostruct [29].

$E_{c}$ is the compressive concrete modulus of elasticity calculated according to the unconfined compressive strength $f_{c}$.

$E_{s e c}$ is a secant modulus of elasticity that corresponds to the confined stress $f_{c c}$ and the ultimate strain $e_{c c}$.

$x, r$ are dimensionless parameters.

The envelop curve mentioned above is shown in Fig. (3) combined with the unloading and reloading rules proposed by Martinez-Rueda and Elnashai [35], as shown in Fig. (4). In Seismostruct [29] five main model parameters must be defined in order to fully describe the mechanical characteristics of concrete:

- The compressive strength - $f_{c}$, which is the compressive stress capacity of a concrete cylinder with dimensions 100x200 mm

- The tensile strength - $f_{t c}$, which is usually assumed to be negligible

- The strain at peak stress $-\varepsilon_{c}$, which is the strain that corresponds to the point of unconfined peak compressive stress $f_{c}$
- The confinement factor - $k_{c}$, that is defined as the ratio between the confined and unconfined compressive stress of the concrete and is calculated based on the transverse reinforcement [33]

- $\quad$ The specific weight.

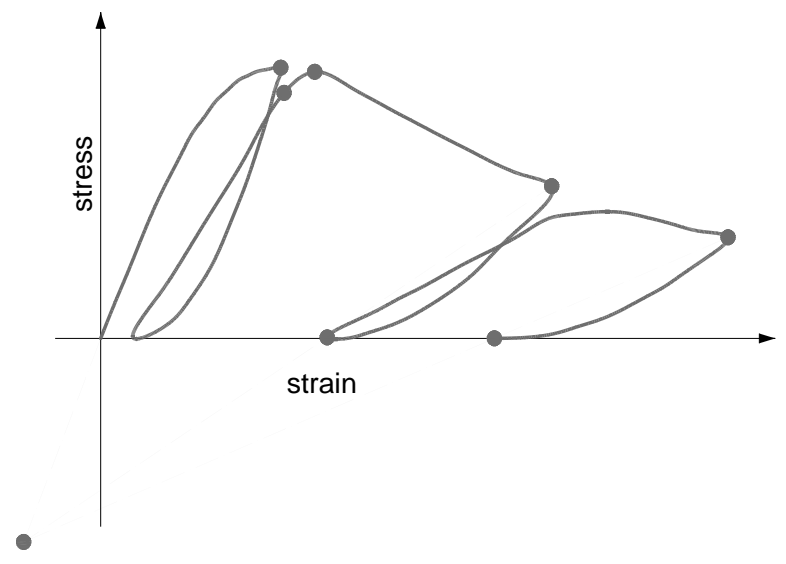

Fig. (4). Unloading and reloading branches for Stress-Strain curves proposed by Martinez-Rueda \& Elnashai [35].

\subsection{Steel Model}

The non-linear model of Menegotto and Pinto [31] as modified by Filippou et al. [32] to include isotropic strain hardening is characterized by the following relationship that represents a curved transition from the elastic to the plastic range

$\sigma^{*}=\mu_{S} \cdot \varepsilon^{*}+\frac{\left(1-\mu_{S}\right) \cdot \varepsilon^{*}}{\left(1+\varepsilon^{* R}\right)^{1 / R}} \cdots$

where:

$\mu_{S} \quad$ is the stiffness reduction factor after yielding

$\mu_{S}=\frac{E_{s h}}{E_{S}} \cdots$

$E_{s}$ and $E_{s h}$ are the initial tangent and the strain hardening modulus of the steel, respectively

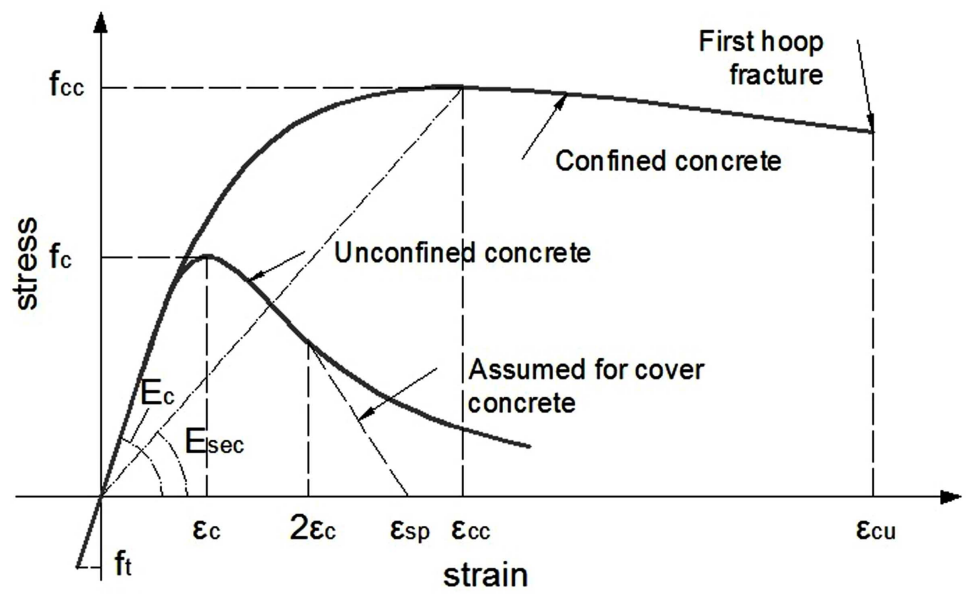

Fig. (3). Stress-Strain model for concrete proposed by Mander et al. [33]. 
$\sigma^{*}$ and $\varepsilon^{*}$ are normalized parameters given from the equations

$\sigma^{*}=\frac{\sigma-\sigma_{r}}{\sigma_{0}-\sigma_{r}} \ldots$

$\varepsilon^{*}=\frac{\varepsilon-\varepsilon_{r}}{\varepsilon_{0}-\varepsilon_{r}} \ldots$

$R$ is a parameter that controls the shape of the transition curve between initial and post-yield stiffness, necessary to accurately represent Baushinger effects and pinching of the hysteretic loops, with initial value $R_{0}$,

$$
R=R_{0}-\frac{a_{1}\left|\frac{\left(\varepsilon_{m}-\varepsilon_{0}\right)}{\varepsilon_{y}}\right|}{a_{2}+\left|\frac{\left(\varepsilon_{m}-\varepsilon_{0}\right)}{\varepsilon_{y}}\right|} \cdots
$$

$a_{1}$ and $a_{2}$ are two coefficients used to calibrate the changes that must be applied to parameter $R_{0}$ in order to obtain the updated transition curve "shape parameter" $R$

$\varepsilon_{m}$ is the experienced maximum tensile or minimum compressive strain

$\varepsilon_{y}=\frac{f_{y}}{E_{S}} \ldots$

$\varepsilon_{y}$ is the yielding strain

$\left(\varepsilon_{r}, \sigma_{r}\right) \quad$ are the coordinates of the point where the last unloading occurred

$\left(\varepsilon_{0}, \sigma_{0}\right)$ are the coordinates of the point intersected by the asymptote of the elastic stiffness and the asymptote of yielding stiffness as depicted in Fig. (5).

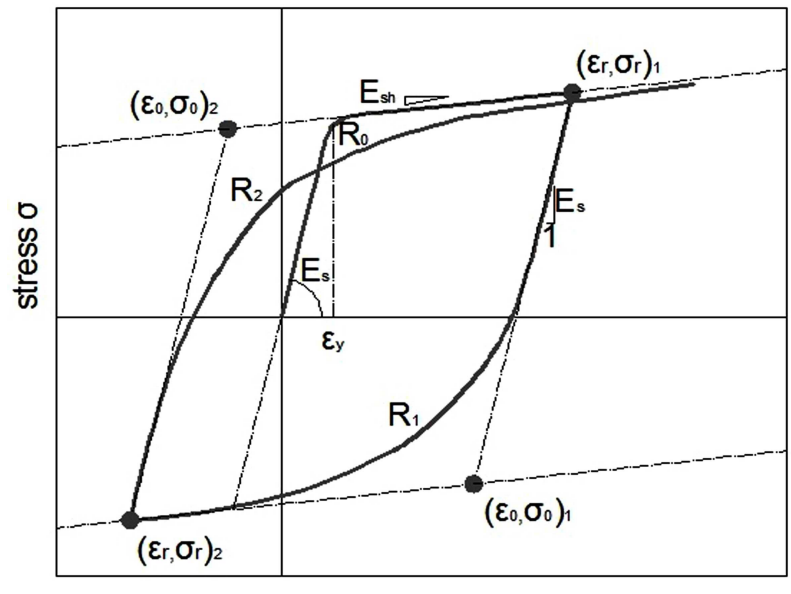

strain $\varepsilon$

Fig. (5). Hysteretic model for steel reinforcement.

\subsection{Masonry Panel Element Model}

As discussed previously the model proposed by Crisafulli [9] uses two pairs of diagonal struts that act mainly under compression and a pair of shear springs that transfer shear loads from the top to the bottom of the panel element across the diagonal under compression. Two different hysteretic rules apply for the total representation of the infill response: (i) a masonry strut hysteresis model for the diagonal struts, and (ii) a bilinear hysteresis rule for the shear springs. In Fig. (6), the two parallel struts per diagonal direction and the two shear strings (one per each diagonal direction) are shown (reproduced from Crisafulli \& Carr [36]). The four dummy nodes shown in Fig. (6) are introduced to account for the contact length between the frame and the infill panel.

The main parameters characterizing this type of element as implemented in Seismostruct [29] and shortly described by Smyrou [19] and Smyrou et al. [37], are the following:

a. Strut Curve Parameters

- Initial Young modulus - $E_{\text {mas }}$. The elastic modulus represents the initial slope of the strain-stress curve and its value exhibits a large variation.

- Compressive strength - $f_{\text {mas }}$. This compressive strength refers to the diagonal capacity of the infill panel and does not represent the standard compressive strength of the masonry. Several equations are available to determine $f_{\text {mas }}$ accounting for different failure mechanisms, in the absence of experimental data [29].

- Tensile strength $-f_{t, \text { mas }}$. The tensile strength represents the tensile strength of the masonry or the bond-strength at interface between frame and infill panel.

- Strain at maximum stress $-e_{m, \text { mas }}$. This parameter represents the strain at maximum stress and influences, via the modification of the secant stiffness, the ascending branch of the stress-strain curve.

- Utimate strain - $e_{u l t, m a s}$. This strain is used to control the descending branch of the stress-strain curve, modelled with a parabola so as to obtain better control of the strut response.

- Closing strain - $e_{c l, m a s}$. This parameter defines the strain after which the cracks partially close allowing compression stresses to develop.

The model proposed by Crisafulli [9] for the cyclic axial behavior of masonry is shown in Fig. (7). The cyclic compressive behavior is represented by six rules that account for loading, unloading, small cycle hysteresis, tensile behavior and local contact effects for cracked masonry are not mentioned here for briefness, since they are available in the original work of Crisafulli [9]. Except from the mechanical parameters needed to describe the response of the diagonal struts, additional nine empirical parameters are needed to determine the hysteresis rules; however, most of them do not have a significant impact on the response, provided that values between the acceptable limits are selected [19, 29, 37]. Sensitivity studies conducted on these empirical parameters [19] have shown that only three of them are important to determine the masonry cyclic response, while they have little influence in pushover analysis:

- Starting unloading stiffness factor - $\gamma_{u n}$. It is used to define, as a proportion of its loading counterpart, the starting unloading stiffness modulus.

- Strain reloading factor $-\alpha_{c h}$. It is employed to predict the strain at which the loop reaches the envelope after unloading. 

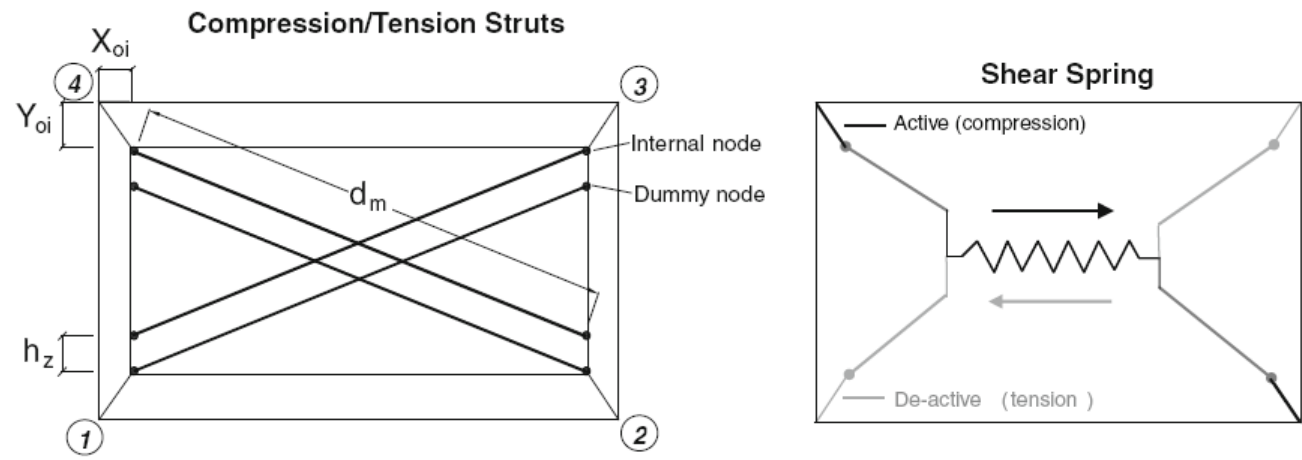

Fig. (6). Four-node panel element model used in this study - reproduced from [36].

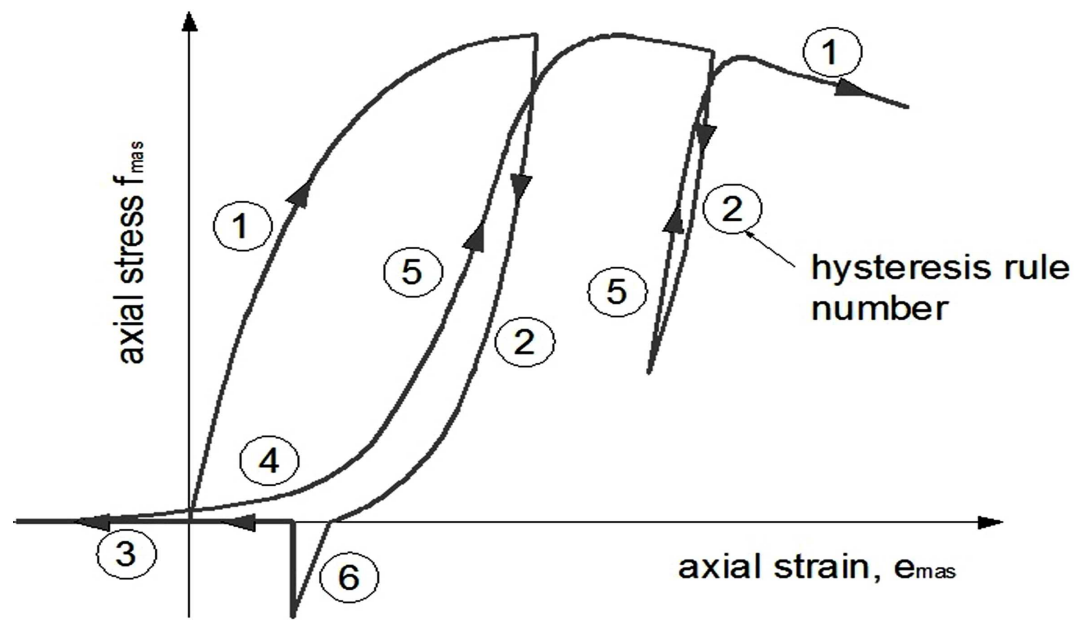

Fig. (7). Masonry strut hysteretic response [9].

- Plastic unloading stiffness factor - $e_{x I}$. It defines, as a proportion of its loading counterpart, the unloading tangent modulus corresponding to the plastic strain. Values ranging from 1.5 and 3.0 have been used (though any value greater than zero constitutes a valid entry), the latter being also the default in SeismoStruct.

The default values have been considered for these parameters.

\section{b. Shear Curve Parameters}

The cyclic shear response of mortar joints is governed by two rules as shown in Fig. (8). While the shear strength is not reached the shear behavior of mortar joints is elastic; thus, the shear deformation $\gamma$ and the shear stress $\tau$, are related according to the equation

$\tau=G_{m} \cdot \gamma \ldots$

where $G_{m}$ is the shear modulus. The maximum shear strength $\tau_{\text {mas }}$, i.e., the largest shear stress that may be mobilized by the infill panel, is evaluated following a bond-failure mechanism according to the following relationship:

$$
\tau_{\text {mas }}=\left\{\begin{array}{cc}
\tau_{0}+\mu_{\text {mas }} \cdot\left|f_{n}\right| & f_{n}<0 \\
\tau_{0} & f_{n} \geq 0
\end{array} \cdots\right.
$$

where:

$\tau_{0}$ is the shear bond strength $\mu_{m a s} \quad$ is the friction coefficient

$f_{n}$ is the compressive stress perpendicular to the mortar joints

The shear stress $\tau_{\max }$ shown in Fig. (8) is an upper value for the shear strength. When the shear strength is reached, the bond between mortar and brick is lost and only the sliding behavior remains, depicted as rule 2 in Fig. (8). The shear stress is given by:

$\tau=\left\{\begin{array}{cl}\mu_{\text {mas }} \cdot\left|f_{n}\right|<\tau_{\max } & f_{n}<0 \\ 0 & f_{n} \geq 0\end{array} \cdots\right.$

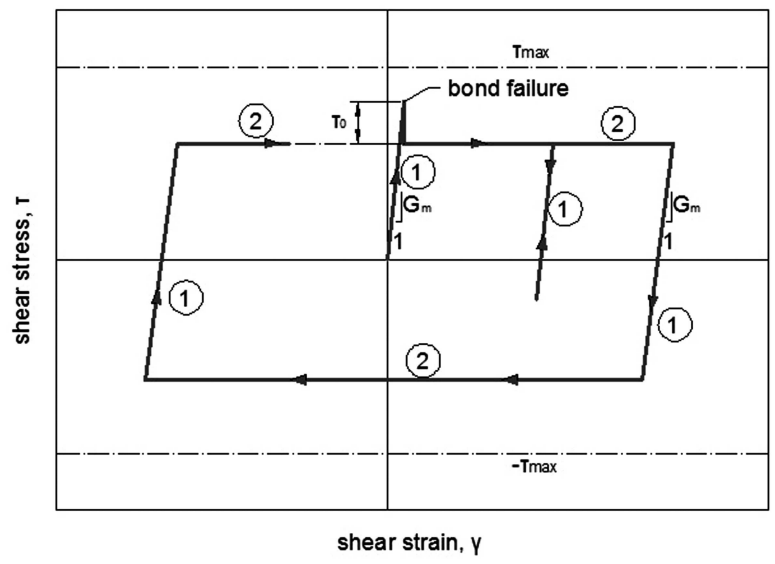

Fig. (8). Cyclic shear response [9]. 


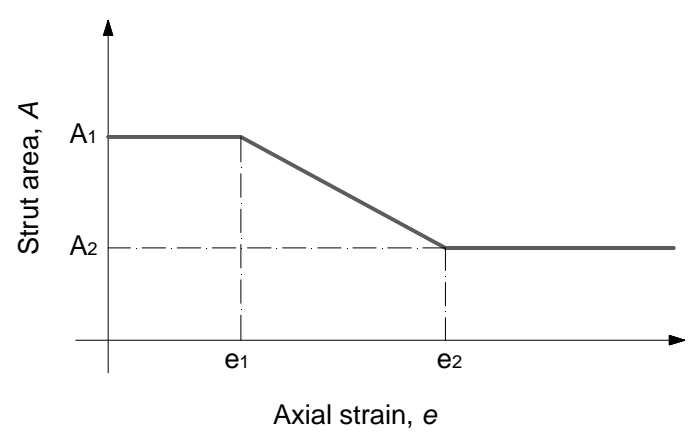

Fig. (9). Variation of strut area depending on axial strain [29].

c. Other parameters

- Infill Panel Thickness $\left(t_{w}\right)$, which may be considered as equal to the width of the panel bricks alone or may also include the contribution of the plaster.

- Strut Area $1\left(A_{1}\right)$, defined as the product of the panel thickness and the equivalent width of the strut $b_{w}$, which normally varies between $10 \%$ and $40 \%$ of the diagonal of the infill panel $d_{m}$, as shown in Fig. (6). Several empirical expressions are available in the literature for the evaluation of $b_{w}$, summarised in [19], while a typical value should be expected to range between $1 / 3$ and $1 / 4$ of $d_{m}$ [38, 39].

- $\quad$ Strut Area $2\left(A_{2}\right)$, introduced as a percentage of $A_{l}$, that aims to account for the fact that the area of strut progressively decreases because of cracking of the infill panel and loss of contact between the frame and the infill. It is assumed that the area decreases linearly as function of the strain as shown in Fig. (9) between the strut area reduction strain $e_{1}$ and the residual strut area strain $e_{2}$.

- Equivalent contact length $\left(h_{z}\right)$, is used to account for the contact length between the frame and the infill panel and is introduced as a percentage of the vertical height of the panel, effectively yielding the distance between the internal and dummy nodes as shown in Fig. (6). Reasonable results seem to be obtained for values of $1 / 3$ to $1 / 2$ of the actual contact length $(\mathrm{z})$, defined by

$z=\frac{\pi}{2 \cdot \lambda} \ldots$

where $\lambda$ is a dimensionless relative stiffness parameter computed by the Equation (8)

$\lambda=\sqrt[4]{\frac{E_{m} \cdot t_{w} \cdot \sin (2 \theta)}{4 E_{c} \cdot I_{c} \cdot h_{w}} \ldots}$

in which $E_{\text {mas }}$ is the elastic modulus of the masonry, $t_{w}$ is the thickness of the panel, $\theta$ is the angle of the diagonal strut with respect to the beams, $E_{c} I_{c}$ is the bending stiffness of the columns, and $h_{w}$ is the height of the infill panel [40]. A $40 \%$ percentage of $z$ is assumed to evaluate the $h_{z}$ in the absence of data on the detailing of the interface between the infill and the surrounding R/C frame of the test specimens [28].

It should be noted that the contact conditions at the panel-frame interface are not directly numerically considered. Crisafulli [9] infill panel model assumes full contact until compressive failure of the struts along the $h_{z}$ length at the compressed corners of the infill panel is reached. The value of $h_{z}$ is selected in order to provide acceptably accurate results for the moments and shears of the surrounding RC members based on experimental data. At the corners of the panel along the tensile diagonal, the contact is lost or the infill panel is cracked when the $f_{t, \text { mas }}$ strength is exceeded. No slipping possibility between the panel and the frame is considered. The present research and other works assessing the accuracy of the proposed infill-panel model based on experimental and analytical results, e.g., [9, 10, 37] prove its capability to accurately describe the response of infill masonry for one- or multi-story planar frames and threedimensional structures; nevertheless, more research is needed to enhance the validity of the model for different mechanical and geometrical properties of the materials and different construction conditions that might allow excessive shear in the panel-frame interface.

\subsection{Trilinear CFRP Model}

A relatively simple trilinear uniaxial model is implemented for the FRP material shown in Fig. (10). This model is fully described by four parameters: (i) tensile strength $f_{t}$, initial stiffness $E_{1}$, post-peak stiffness $E_{2}$, and specific weight. The FRP material looses its strength very sharply upon rupture; however, a finite value is usually assigned to the post-peak stiffness $E_{2}$ to avoid numerical instability of the analyses. The value of $E_{l}$ was based on the volumetric percentage of fibers and resin according to

$$
E_{1}=\frac{E_{f} \cdot V_{f}+E_{r} \cdot V_{r}}{V_{f}+V_{r}} \ldots
$$

where $E$ and $V$ are modulus of elasticity and volume, respectively, and the subscripts $f$ and $r$ denote the carbon fibers and the resin, respectively $[3,4]$. Since bond failure is difficult to model without the application of a more sophisticated procedure, the tensile strength $f_{t}$ of the FRP was determined so that the failure occurs for the same axial deformation with the experiment; thus, in the analytical model the CFRP reaches its full tensile strength that is smaller than the original.

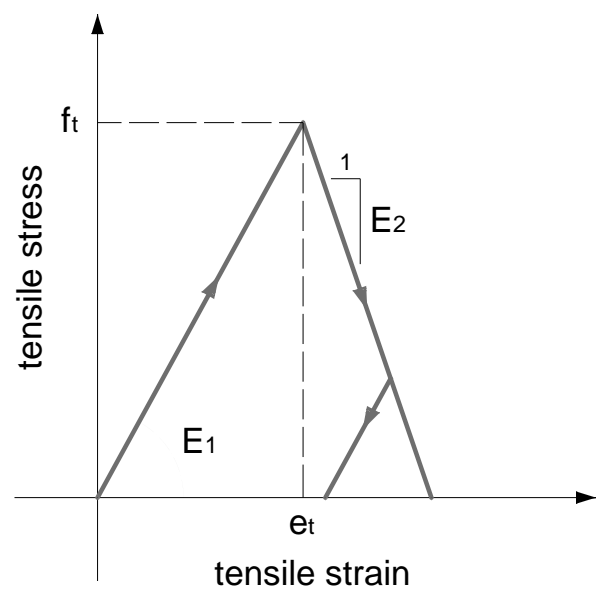

Fig. (10). Trilinear uniaxial model for the FRP material [29].

\section{ANALYTICAL RESULTS}

Two types of analyses were contacted, namely: (a) static non-linear analysis; and (b) quasi-static (cyclic) analysis, in 
order to: (i) compare with the experimental results; and (ii) determine "critical parameters" for the analysis.

The static non-linear analysis consisted of a Load Control phase and a subsequent Displacement Control phase and aimed to determine the capacity curve of the frames under lateral loads. A triangular load distribution was selected during the first phase, so that the load at the second floor level was always twice the load applied at the first floor. For $U_{1}$ frame, loading at the level of the second floor only was considered, as was applied during the experiment [28]. Subsequently, a Displacement Control phase follows till the desired roof displacement was reached. The load factor and the total number of steps for the two phases were different for each frame.

The second type of analysis was identical in terms of considtions and loading protocol to the experiments performed by Akgüzel [28]. A pseudo-dynamic analysis was performed, modelling the cyclic loading of the experiments. More specifically, cyclic forces were imposed at both storey levels up to yield and then displacements were imposed till failure occurred, with the exception of the bare frame where only the second floor was loaded as mentioned above. The experimental results were used to estimate the values of critical parameters of the analytical models. This assessment was made by comparing the capacity curves that resulted from the non-linear static analyses for several values of these parameters with the corresponding backbone curves that resulted as envelopes of the lateral load-displacement hysteretic curves obtained from the experiments.

\subsection{Validation of $U_{I}$ Frame}

The characteristic parameters of the concrete and the steel of the reinforcement were determined to account thoroughly for the response of the bare frame $U_{1}$. The lateral load-displacement curve for the cyclic test is shown in Fig. (11), while the back-bone curve has been obtained after connecting the points of maximum force and displacement for each cycle.

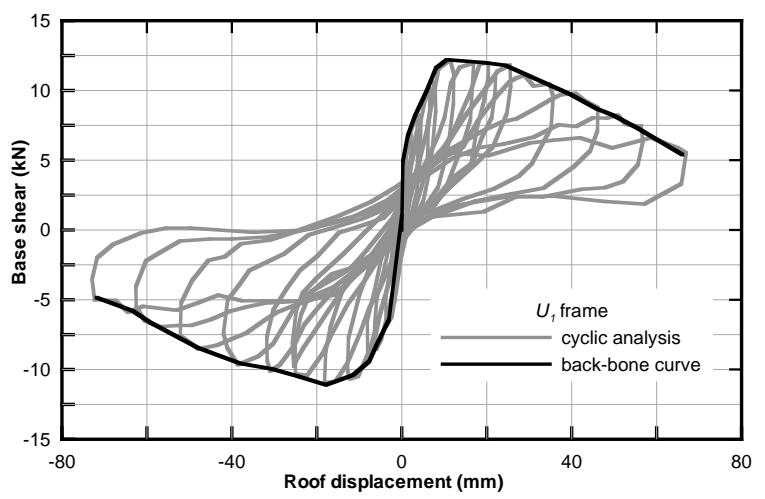

Fig. (11). $U_{1}$ frame: Lateral load-displacement curve and backbone curve according to the experimental results [28].

Since the strength and the modulus of elasticity of the materials were already known [28], the following parameters had to be calibrated from the comparison with the experimental results: (i) the strain hardening parameter, $\mu$; and (ii) the strain of concrete at peak stress, $\varepsilon_{c}$ [29]. As mentioned above, the overlap length of the longitudinal bars of the rein- forcement at the base of each floor was inadequate (equal to $160 \mathrm{~mm}$, twenty times the diameter of bars). Therefore, it was expected that bond slip would occur prior to yielding of the reinforcement. An accurate modelling of the bond slip would require the use of a more sophisticated model, which was out of the scope of the present research. On the other hand, the assumption that no bond slip occurs allows the reinforcement to develop its full strength, which was not the case in the experiments, thus differences from the experimental data were expected. In order to reduce the error, we assumed full bond of the rebars, but reduced the yield strength of the steel. In Fig. (12) the pushover curves for several values of the yield strength, $f_{y}$, are presented and compared to the experimental backbone curve. Notice that in the following figures where several values of a parameter are examined, the solid continous black line always determines the finally selected value. It is found that a value of $f_{y}=165$ $\mathrm{MPa}$ results in an acceptable fit; thus, a reduction of $f_{y}$ to $\sim 45 \%$ of its nominal value was applied to account for the inadequate bond. Such an approximation is valid, since the primary objective of this research was to focus on the CFRP effects and on the modelling of infilled frames.

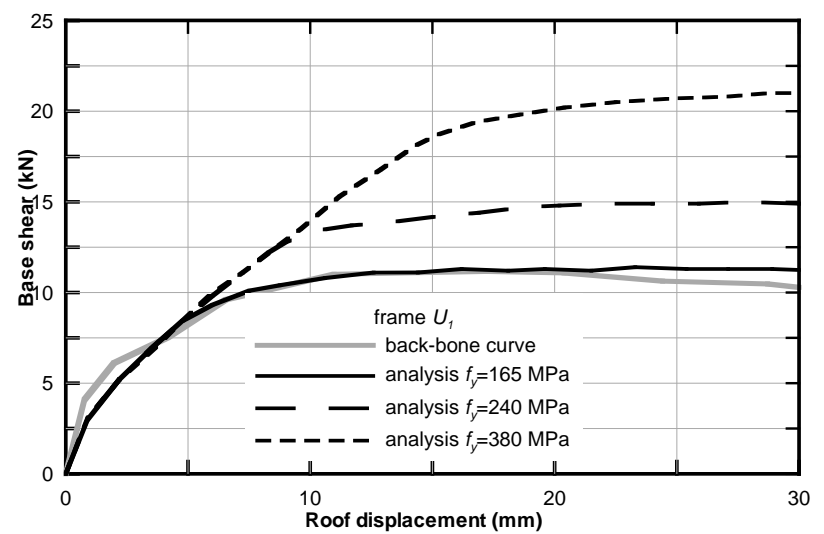

Fig. (12). $U_{1}$ frame Load-displacement pushover curves for the determination of the yield strength $f_{y} ; E_{s}=195 \mathrm{GPa} ; \mu_{s}=0.005 ; f_{c}$ $=15.40 \mathrm{MPa} ; \varepsilon_{c}=0.002$.

A similar investigation was performed in order to determine the strain hardening parameter $\mu$. As expected, this parameter affected the inelastic response of the frame structure. An increase in its value resulted in an increase in the lateral load capacity. As shown in Fig. (13), $\mu=0.00$ is the most acceptable value.

In Fig. (14), the effect of the strain of the concrete at peak stress $\varepsilon_{c}$ is shown. It is evident that this parameter does not affect the response significantly, thus a value of $\varepsilon_{c}=$ 0.00128 was selected. It is observed that, for the selected values of the critical parameters $f_{y}$ and $\mu$, a very satisfying match is achieved between the analytical results of static pushover analysis and the envelope of the experimental results for lateral load and displacement. The inelastic and plastic behaviour of the frame is simulated with acceptable accuracy regarding the shape and the maximum values. As shown in Fig. (14), in the experiment the maximum base shear was $11.16 \mathrm{kN}$ and corresponded to roof displacement $17.2 \mathrm{~mm}$, while the corresponding values of the analytical model were: maximum base shear $11.07 \mathrm{kN}$ at $20.3 \mathrm{~mm}$ roof displacement. 


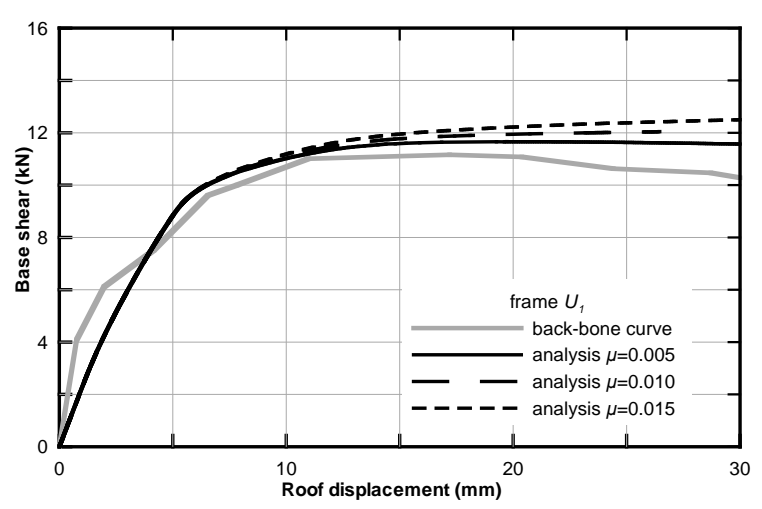

Fig. (13). $U_{1}$ frame: Load-displacement curves for the determination of strain hardening parameter $\mu ; f_{y}=165 \mathrm{MPa} ; E_{s}=195 \mathrm{GPa} ; f_{c}$ $=15.40 \mathrm{MPa} ; \varepsilon_{c}=0.002$.

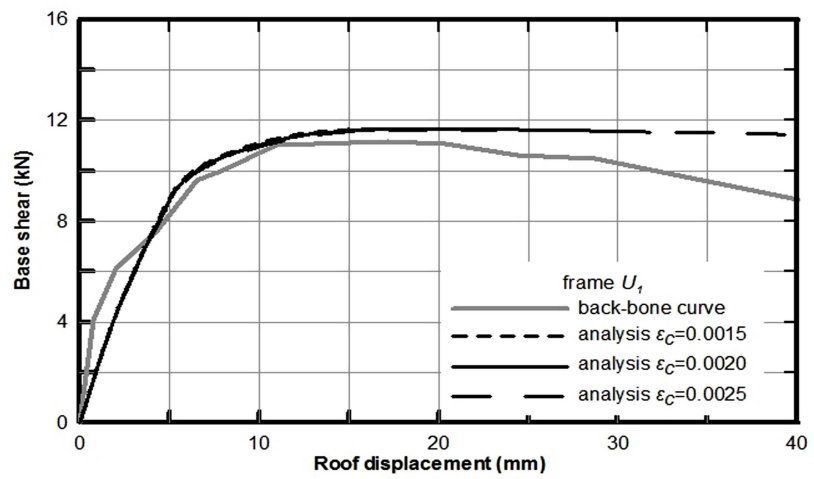

Fig. (14). $U_{1}$ frame: Load-displacement pushover curves for the determination of the concrete strain at the peak stress $\varepsilon_{c} ; f_{y}=165$ $\mathrm{MPa} ; E_{s}=195 \mathrm{GPa} ; \mu_{s}=0.005 ; f_{c}=15.40 \mathrm{MPa}$.

The final results of the cyclic analysis are presented in Fig. (15) and compared with the experimentally derived curves. It is seen that the maximum base shear at each cycle and the corresponding rood displacement of the analytical model are similar to those of the experiment. However, the experimentally and analytically obtained load-displacement loops differ significantly, especially during the unloading phase. More specifically, in the experiment, the stiffness during unloading was decreasing progressively and the loops were narrower around the origin compared to the hysteretic loops of the analysis. This phenomenon, known as pinching that is attributed to bond slip at the overlap regions is difficult to analytically capture.

In Fig. (15) no pinching is observed and the loops during unloading had slope nearly equal to the elastic stiffness. Pinching is controlled by the parameter $R_{0}$ and the coefficients $a_{1}$ and $a_{2}$ of the Menegotto \& Pinto steel model [31] as discussed previously in Section 3.2. Modifying the values of these quantities through a parametric evaluation, a better fit of the analytical and experimental results is achieved, as shown in Fig. (16). Note that the values of $R_{0}, a_{1}$ and $a_{2}$ not mentioned in the captions of Figs. $(12,13$ and 14) are the default values of the model mentioned in the caption of Fig. (15). A slight deviation from the analytical results still remains. This happened because full bond of the rebars was considered and the effect of the bond slip was taken under consideration with the reduction of the yield stress, as described above; however, this approximation slightly affected the response of the frames with infill walls, as will be shown in the following sections.

It is noted that the experimentally measured displacements during the few last cycles of loading were greater than the ones described in the loading protocol in [28], suggesting probably an inadequate lateral support of the specimens during the experiment. This introduced a significant difference compared to the analytical model, in which the imposed deformation was applied according to the loading protocol; as a result, the maximum attained displacements were smaller.

\subsection{Validation of $U_{2}$ Frame}

In the development of $U_{2}$ frame model, the values of the parameters for concrete and steel determined for $U_{1}$ frame were used.The applied loading protocol was similar to the one applied to the $U_{1}$ frame. The experimental results for base shear and the roof displacement for the cyclic loading and the corresponding backbone curve are shown in Fig. (17). In this case, the comparison of analytical and experimental results was used to calibrate the parameters of the masonry panel element by Crisafulli [9] that was used. The effects of the inherent uncertainties involved with the masonry properties on the assessment of infill frame response were also quantified with the use of experimental data [41].

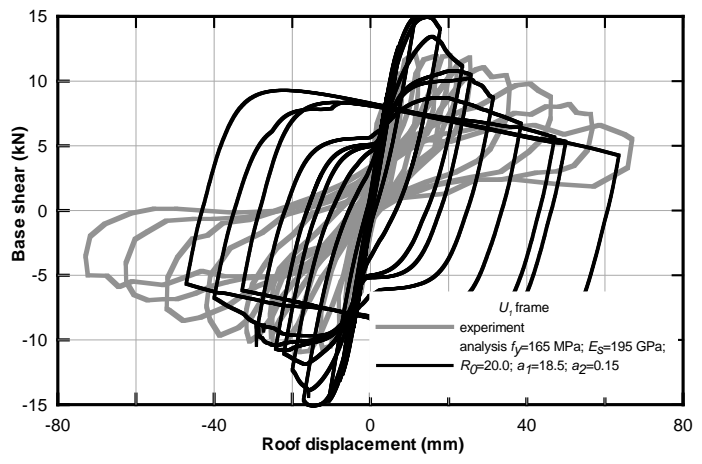

Fig. (15). $U_{1}$ frame: Comparison of the experimentally and the analytically derived load-displacement curves for cyclic loading. The parameters used in the analytical model are; $f_{y}=165 \mathrm{MPa} ; E_{s}=$ $195 \mathrm{GPa} ; \mu_{s}=0.005 ; f_{c}=15.40 \mathrm{MPa} ; \varepsilon_{c}=0.002 ; R_{0}=20.0 ; a_{l}=18.5$; $a_{2}=0.15$.

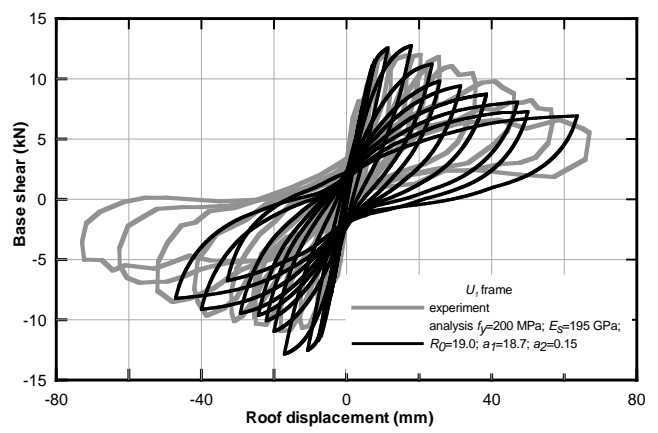

Fig. (16). $U_{1}$ frame: Comparison of the experimentally and the analytically derived load-displacement curves for cyclic loading. The parameters used in the analytical model are; $f_{y}=200 \mathrm{MPa} ; E_{s}=$ $195 \mathrm{GPa} ; \mu_{s}=0.005 ; f_{c}=15.40 \mathrm{MPa} ; \varepsilon_{c}=0.002 ; R_{0}=19.0 ; a_{l}=18.7$; $a_{2}=0.15$.

For a detailed presentation of the parameters characterising the model developed by Crisafulli [9] and their effects on 
the overall response of masonry, the reader is referred to the work of Smyrou et al. [37]. Some of the parameters of the numerical model can be directly evaluated from the known geometrical characteristics of the masonry wall [28], e.g. the panel thickness. The parameters of the model that cannot be determined from the available data are the following: (i) the compressive strength $f_{\text {mas }}$ and the modulus of elasticity $E_{\text {mas }}$ of the masonry; (ii) the residual strut area strain $e_{2}$; (iii) the friction coefficient of the masonry $\mu_{\text {mas }}$; (iv) the shear bond strength $\tau_{0}$ and the maximum shear strength $\tau_{\max } ;(\mathrm{v})$ the residual strut area $A_{2}$; (vi) the ultimate strain $e_{u \text {,mas }}$; (vii) the strain at maximum stress $e_{m, \text { mas }}$; (viii) the closing strain $e_{c l, \text { mas }}$. The basic mechanical properties, usually determined by simple test series, were not available from the experimental data [28]; thus, their determination was based also on the parametric analyses conducted, starting from reasonable assumptions.

In Fig. (18), the comparison of the analytical results with the experimental data is presented for various combinations of $f_{\text {mas }}$ and $E_{\text {mas }}$ that satisfy the relationship proposed by Paulay and Priestley [38], i.e. $E_{\text {mas }}=1000 \times f_{\text {mas }}$. The optimum fit was achieved for $f_{\text {mas }}=3.5 \mathrm{MPa}$ and $E_{\text {mas }}=3500$ $\mathrm{MPa}$; however, a perfect match could not be obtained, especially regarding the displacements at which the maximum shear was attained and the horizontal branch of the pushover curve started. The calibration of the other parameters, and especially of the residual strut area strain $e_{2}$, aimed to correct the mismatch and to lead to a better assessment of the cyclic behaviour.

The area of the equivalent strut strain $e_{2}$ successively reduces with the increase of the lateral displacement and the development of the cracking. The strain $e_{2}$ characterises the end of the strut section reduction, so it is related to the strain at which the frame reaches its maximum resistance. In Fig. (19), the results of static non-linear analyses for different values of $e_{2}$ are shown.

It is observed that an increase in the deformation $e_{2}$ results in an increase in the displacement at which the frame reaches its ultimate resistance and also causes a strong amplification of the resistance itself. This happens because a larger value of $e_{2}$ delays the reduction of the strut cross section, so it amplifies the deformation and the roof displacement that correspond to the maximum resistance. Moreover, due to the lesser reduction of its cross section, the strut can resist with larger force for the same roof displacement, which explains the increased lateral resistance of the infill frame.

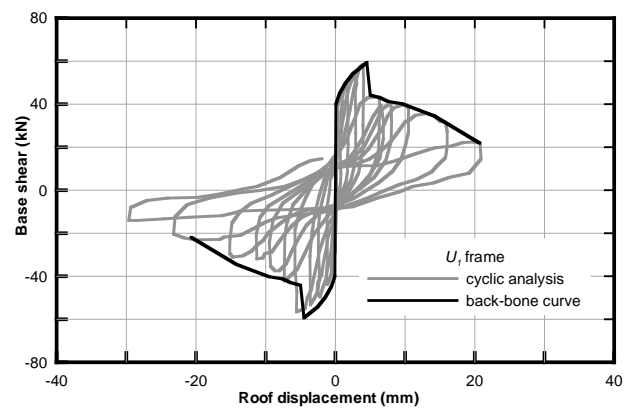

Fig. (17). $U_{2}$ frame: Lateral load-displacement curve and backbone curve according to the experimental results [28].

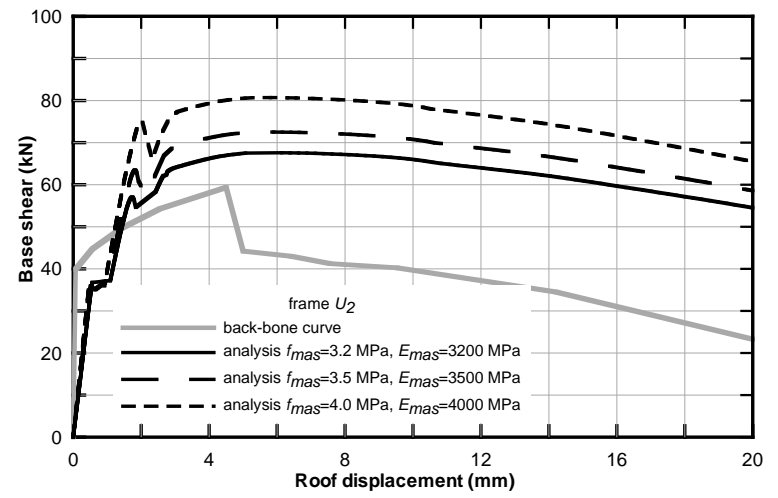

Fig. (18). $U_{2}$ frame: Load-displacement curves for the determination of the masonry compressive strength $f_{\text {mas }}$ and the modulus of elasticity $E_{\text {mas }} ; e_{2}=0.0006 ; \mu_{\text {mas }}=1.20 ; \tau_{0}=700 \mathrm{kPa} ; \tau_{\max }=1200$ $\mathrm{kPa} ; A_{2}=15 \% ; e_{u, \text { mas }}=0.024 ; e_{m, \text { mas }}=0.0012 ; e_{c l, \text { mas }}=0.003$.

In Fig. (20), the response for various combinations of $f_{\text {mas }}, E_{\text {mas }}$ and $e_{2}$ is presented; based on these results, the values selected were: $f_{\text {mas }}=1.65 \mathrm{MPa}, E_{\text {mas }}=1700 \mathrm{MPa}$ and $e_{2}$ $=0.002$. The value of $f_{\text {mas }}=1.65 \mathrm{MPa}$ for the compressive strength of the masonry suggests very low resistance, which should not be considered as unusual for existing structures, especially those with poor mechanical properties of mortar $[42,43]$.

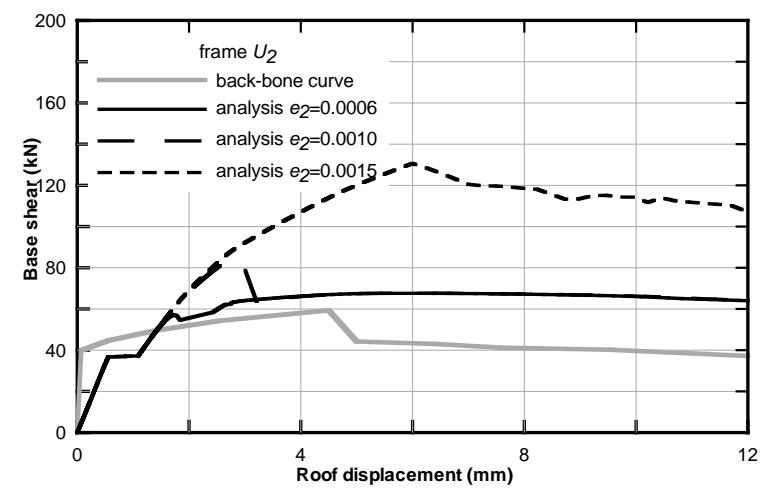

Fig. (19). $U_{2}$ frame Load-displacement pushover curves for the determination of the residual strut area strain $e_{2} ; f_{\text {mas }}=3.20 \mathrm{MPa}$; $E_{\text {mas }}=3200 \mathrm{MPa} ; \mu_{\text {mas }}=1.20 ; \tau_{0}=700 \mathrm{kPa} ; \tau_{\max }=1200 \mathrm{kPa} ; A_{2}=$ $15 \% ; e_{u, \text { mas }}=0.024 ; e_{\text {m,mas }}=0.0012 ; e_{c l \text { mas }}=0.003$.

Note that in the ascending branch of the pushover curve for the selected parameters, shown in Fig. (20), two small horizontal plateaus are observed: the first one corresponds to base shear approximately equal to $40 \mathrm{kN}$ and the second one to base shear about $50 \mathrm{kN}$. This response is attributed to failures in the diagonal struts that simulate the small tensile resistance of the masonry. When tensile failure of masonry is observed an almost instantaneous redistribution of forces takes place, i.e., the axial forces in the compressive struts and the shear loads in the frame columns suddenly increase at a nearly constant overall shear load. The first horizontal plateau corresponds to the failure of the tensile struts in the first floor and the second one to the failure of the tensile struts in the second floor.

The friction coefficient of the masonry model, $\mu_{\text {mas }}$, the shear bond strength, $\tau_{0}$, and the maximum shear strength, $\tau_{\max }$, do not significantly affect the pushover curve and the 
cyclic behaviour. A parametric study on the friction coefficient revealed that the increase of $\mu_{\text {mas }}$ results in trivial modification of the resistance; thus, the maximum value, $\mu_{\text {mas }}$ $=1.20$, was selected as most appropriate, as also suggested in the literature [38]. Similarly, the response of the frame was practically unaffected from the variation of the parameters $\tau_{0}$ and $\tau_{\max }$ within the limits of acceptable values; therefore, values consistent with the selected friction coefficient were considered: $\tau_{0}=700 \mathrm{kPa}$ and $\tau_{\max }=1200 \mathrm{kPa}$.

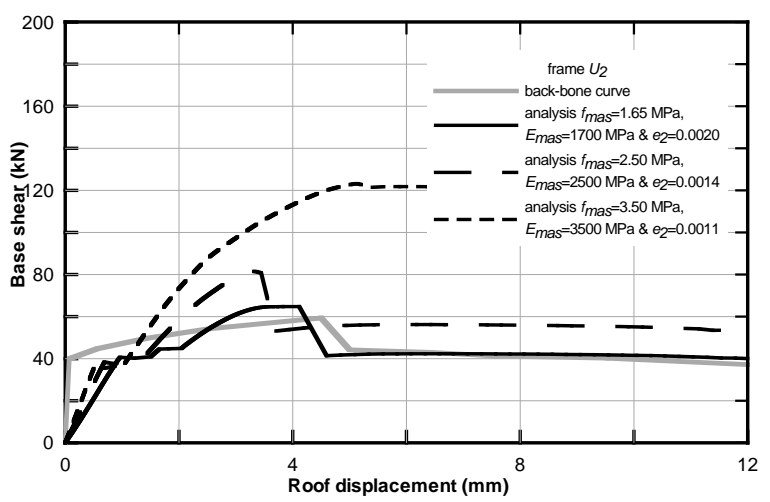

Fig. (20). $U_{2}$ frame: Load-displacement curves for various combinations of $f_{\text {mas }}, E_{\text {mas }}$ and $e_{2} ; \mu_{\text {mas }}=1.20 ; \tau_{0}=700 \mathrm{kPa} ; \tau_{\max }=1200$ $\mathrm{kPa} ; A_{2}=15 \% ; e_{u, \text { mas }}=0.024 ; e_{m, \text { mas }}=0.0012 ; e_{c l, \text { mas }}=0.003$.

The residual strut area $A_{2}$ had a more significant effect on the structural response, as expected. As shown in Fig. (21), an increase in the strut area $A_{2}$ resulted in increased residual resistance of the masonry, but the maximum resistance was not much affected. Also, the characteristic roof displacements were not affected by the variation of $A_{2}$. Based on these results, the value $A_{2}=15 \%$ was selected, which implies that the final section of the strut was equal to $15 \%$ of the original.

In Fig. (22) pushover curves are shown for different values of the ultimate strain $\varepsilon_{u l t}$. It is observed that this parameter affects the response of the frame exclusively at large deformation. In particular, a larger value of $\varepsilon_{u l t}$ leads to a milder drop in the residual lateral resistance. The value $e_{u, \text { mas }}$ $=0.012$ was chosen, because it leads to results closest to the experimental data.

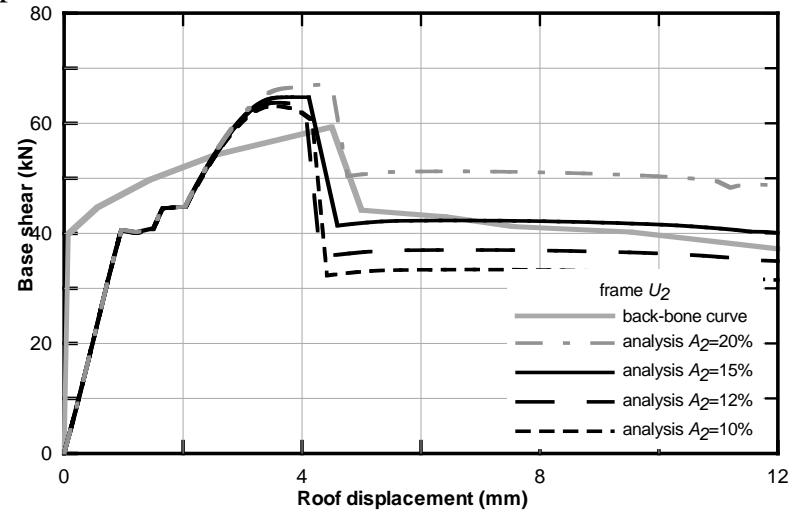

Fig. (21). $U_{2}$ frame: Load-displacement curves for the determination of residual strut area $A_{2} ; f_{\text {mas }}=1.65 \mathrm{MPa} ; E_{\text {mas }}=1700 \mathrm{MPa} ; e_{2}$ $=0.002 ; \mu_{\text {mas }}=1.20 ; \tau_{0}=700 \mathrm{kPa} ; \tau_{\max }=1200 \mathrm{kPa} ; e_{u, \text { mas }}=0.024$; $e_{m, \text { mas }}=0.0012 ; e_{c l, \text { mas }}=0.003$.
A similar investigation on the effect of the peak strain at maximum stress $e_{m, m a s}$ is shown in Fig. (23). It seems that the ultimate lateral resistance of the frame decreases with $e_{m \text {,mas }}$, while the roof displacement that corresponds to the maximum lateral force increases. This occurs because the reduction in the strut sectional area begins before the masonry model develops its total strength. The selected value for $e_{m}$, mas was 0.0014 .

Regarding the determination of the strain $e_{c l \text { mas }}$ after which the cracks partially close allowing for compression stresses to develop, the default value of $\varepsilon_{c l, \max }=0.003$ was used, since this parameter does not seem to affect the response of the model, as depicted in Fig. (24).

The final comparison of the obtained pushover curve with the backbone curve for specimen $U_{2}$ is shown in Fig. (24). It is seen that the analytical model can capture satisfactorily the shape of the backbone curve and can describe the overall behaviour of the infill frame with acceptable accuracy for both the elastic and the inelastic range of deformations. In the experiment, the maximum recorded base shear was $59.64 \mathrm{kN}$ and occurred at roof displacement equal to $3.74 \mathrm{~mm}$. The corresponding values of the pushover analysis with the proposed model were quite similar, specifically, base shear $62.64 \mathrm{kN}$ at roof displacement equal to $3.71 \mathrm{~mm}$. Also, the residual resistance was similar: $40.22 \mathrm{kN}$ for both the analytical and the experimental results with a small difference in the roof displacement at which the final plateau starts. Note that the two horizontal plateaus in the ascending branch of the pushover curve of the analytical model correspond to axial failure of the tensile struts, as mentioned above.

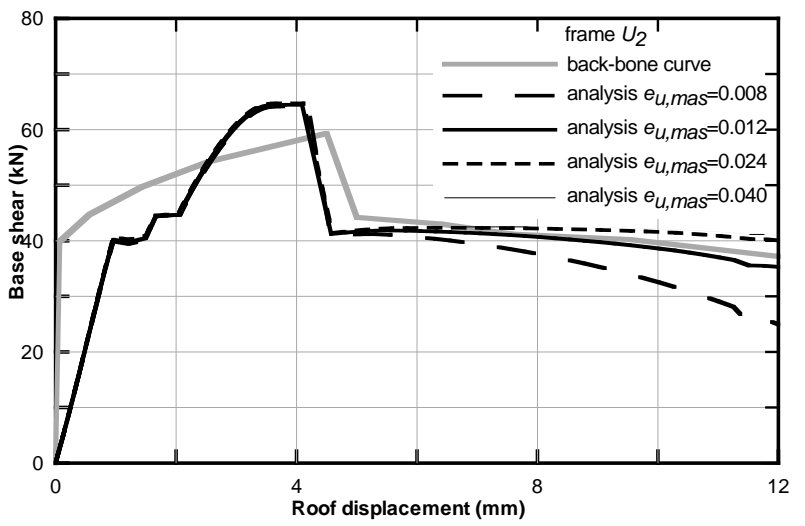

Fig. (22). $U_{2}$ frame: Load-displacement curves for the determination of ultimate strain, $\varepsilon_{u, \text { mas }} ; f_{\text {mas }}=1.65 \mathrm{MPa} ; E_{\text {mas }}=1700 \mathrm{MPa} ; e_{2}$ $=0.002 ; \mu_{\text {mas }}=1.20 ; \tau_{0}=700 \mathrm{kPa} ; \tau_{\max }=1200 \mathrm{kPa} ; A_{2}=15 \%$; $e_{\text {m,mas }}=0.0012 ; e_{c l, \text { mas }}=0.003$.

Very good fit was also achieved for the cyclic loading. The maximum base shear of each cycle and the corresponding roof displacement according to the experiment and the analytical model nearly coincide, as shown in Fig. (25). The analytical model can also predict the shape of the hysteretic loops, capturing very well the sequence of failures in the test specimen.

\subsection{Validation of $U_{3}$ Frame}

In the third model $U_{3}$, the parameters defined for the concrete, the steel and the masonry from the calibration of the 
analytical model with the experimental data for the specimens $U_{1}$ and $U_{2}$ were retained and the parametric investigation was focused on the calibration of the parameters for the FRP. Specifically, the parameters used for the frame and the infill masonry were: $f_{y}=165 \mathrm{MPa} ; \mu=0.00 ; \varepsilon_{c}=0.00128 ; f_{\text {mas }}$ $=1.65 \mathrm{MPa} ; E_{\text {mas }}=1700 \mathrm{MPa} ; e_{2}=0.002 ; \mu_{\text {mas }}=1.20 ; \tau_{0}=$ $700 \mathrm{kPa} ; \tau_{\max }=1200 \mathrm{kPa} ; A_{2}=15 \% ; e_{u, \text { mas }}=0.012 ; e_{m, \text { mas }}=$ $0.0014 ; e_{c l, m a s}=0.003$. The loading protocol applied in specimen $U_{3}$ was similar to that for the other two specimens, consisting of a force-based phase followed by a displacement-based phase, as described earlier. In Fig. (26), the cyclic response and its backbone envelope are shown.

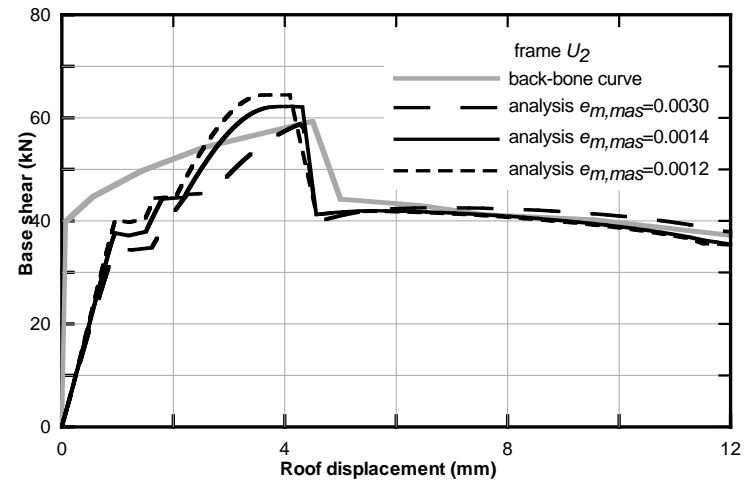

Fig. (23). $U_{2}$ frame: Load-displacement curves to determine the peak strain at maximum stress, $e_{\text {m,mas }} ; f_{\text {mas }}=1.65 \mathrm{MPa} ; E_{\text {mas }}=1700$ $\mathrm{MPa} ; e_{2}=0.002 ; \mu_{\text {mas }}=1.20 ; \tau_{0}=700 \mathrm{kPa} ; \tau_{\max }=1200 \mathrm{kPa} ; A_{2}=$ $15 \% ; e_{u, \text { mas }}=0.012 ; e_{c l \text { mas }}=0.003$.

The difference of specimen $U_{3}$ from specimen $U_{2}$ concerns only the strengthening with the CFRP. The parameters that define the response of the FRP are: (i) the tensile strength $f_{i}$; (ii) the initial modulus of elasticity $E_{1}$; and (iii) the post-peak modulus of elasticity $E_{2}$. According to Akgüzel [28], debonding of the FRP was observed due to insufficient anchorage of CFRP sheets on the frame-wall structure.

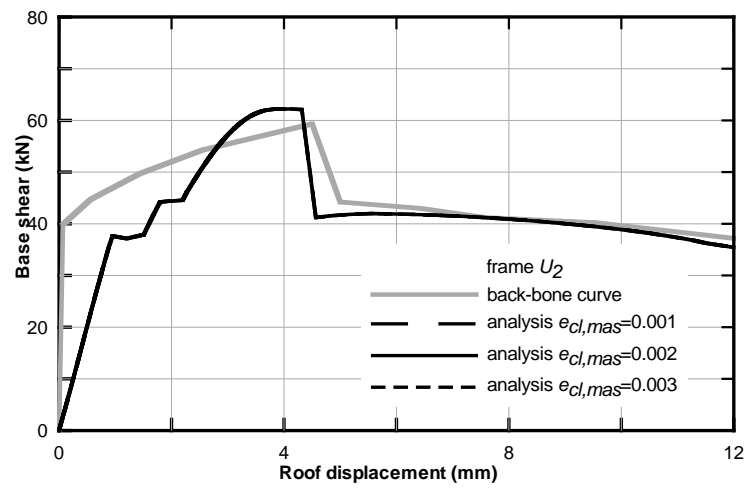

Fig. (24). $U_{2}$ frame: Load-displacement pushover curves to determine the closing strain, $e_{c l \text { mas }} ; f_{\text {mas }}=1.65 \mathrm{MPa} ; E_{\text {mas }}=1700 \mathrm{MPa} ; e_{2}$ $=0.002 ; \mu_{\text {mas }}=1.20 ; \tau_{0}=700 \mathrm{kPa} ; \tau_{\max }=1200 \mathrm{kPa} ; A_{2}=15 \% ; e_{u, \text { mas }}$ $=0.012 ; e_{m, \text { mas }}=0.0014$.

In order to accurately account for this type of failure, and since a more complex model was not used, the selection of the parameters was made so that the FRP had smaller ultimate tensile strength than the one measured during the experiments, which was defined from the maximum axial strain developed at debonding. The modulus of elasticity was evaluated as the volumetric average of the moduli of the individual materials, i.e. the fibres and the epoxy, resulting in $f_{t}$ $=953 \mathrm{MPa}$ and $E_{1}=130000 \mathrm{MPa}$. The post-peak modulus of elasticity was set equal to the initial modulus $E_{2}=E_{1}$, since it was found that the response was practically unaffected by this parameter because the post-peak stiffness affected the response of the FRP at displacements greater than the displacements imposed on the test specimen. Using these values for the parameters, the comparison of the analytically predicted response with the experimental data for the FRP strengthened RC brick infilled frame are presented in Figs (27 and 28) for monotonic and cyclic loading, respectively.

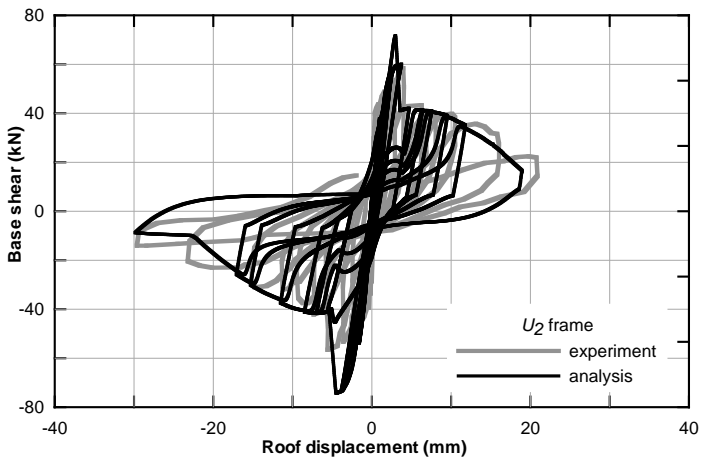

Fig. (25). $U_{2}$ frame: Comparison of experimentally and analytically derived load-displacement curves for cyclic loading for $f_{\text {mas }}=1.65$ $\mathrm{MPa} ; E_{\text {mas }}=1700 \mathrm{MPa} ; e_{2}=0.002 ; \mu_{\text {mas }}=1.20 ; \tau_{0}=700 \mathrm{kPa} ; \tau_{\max }=$ $1200 \mathrm{kPa} ; A_{2}=15 \% ; e_{u, \text { mas }}=0.012 ; e_{\text {m,mas }}=0.0014 ; e_{c l, \text { mas }}=0.003$.

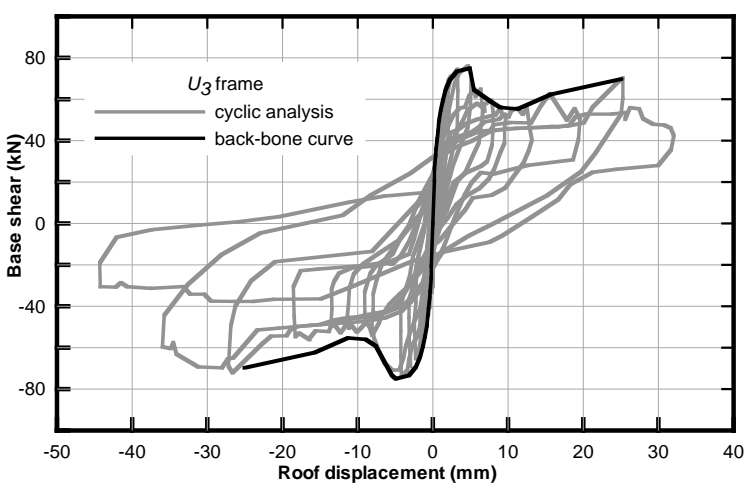

Fig. (26). $U_{3}$ frame: Lateral load-displacement curve and corresponding backbone curve according to the experimental results [28].

Regarding the monotonic behaviour, good agreement was achieved concerning the ultimate resistance to lateral loading: in the experiment, this value was $76.23 \mathrm{kN}$ and occurred at roof displacement equal to $4.87 \mathrm{~mm}$, while the corresponding value of the analytical model was $71.55 \mathrm{kN}$ at 4.26 $\mathrm{mm}$ roof displacement. However, significant discrepancy of the analytical results from the experimental data appears for large displacements, specifically for roof displacement larger than $15 \mathrm{~mm}$, as shown in Fig. (27). More specifically, a steep strength decrease occurred in the analytical model after roof displacement equal to $16 \mathrm{~mm}$, while the corresponding drop in strength in the test specimen occurred after $25 \mathrm{~mm}$. The difference is attributed to the different way in which the loading was implemented: in the experiment, the test specimen was partially blocked in order to follow the imposed displacement at each step [28], while the analytical model 
under monotonic loading was free under lateral deformations till collapse. Thus, several types of failure that occurred in the analytical model could not be developed during the test at the same level of displacement, but at larger deformation. An example of such a failure concerns the formation of plastic hinges at the top and the base of the columns of the second floor, which occurred during the pushover analysis and lead to significant loss of resistance. The two small plateaus at base shear equal to $43 \mathrm{kN}$ and $64 \mathrm{kN}$ that are shown on the elastic ascending branch of the pushover curve correspond to the axial failure of the tensile diagonal struts of the masonry panel element, as noted earlier.

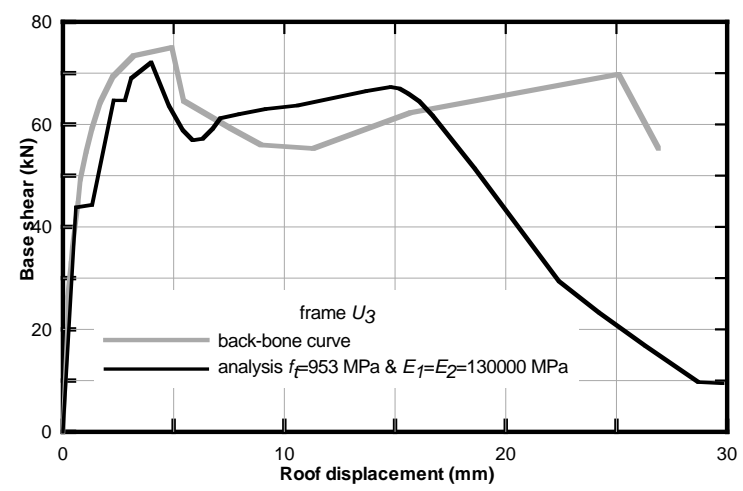

Fig. (27). $U_{3}$ frame: Load-displacement pushover curve and comparison with experimental backbone curve for $f_{t}=953 \mathrm{MPa}$ and $E_{1}$ $=E_{2}=130000 \mathrm{MPa}$.

The predicted cyclic response was also very good, as shown from the comparison with the experimental data depicted in Fig. (28). Some differences between the analytical results and the load-displacement loops obtained from the experiment that occurred during the few last cycles are attributed to the fact that in the test the specimen was allowed to deform beyond the displacement that corresponded to the loading protocol. Thus, there was a mismatch between the assumed imposed displacements according to the loading history and the measured ones, as depicted in the cyclic loops [28]. In the numerical analysis, the loading protocol

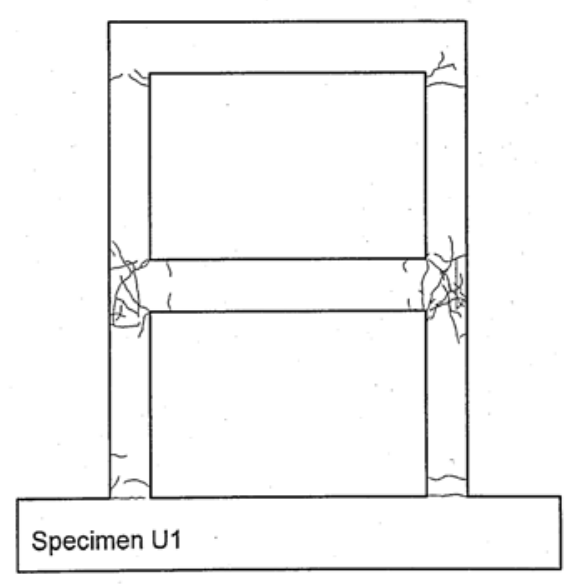

(a) Final crack pattern from the experiment - reproduced from [28].

Fig. (29). Failure modes for specimen $U_{l}$. was followed, thus the displacements were smaller. Apart of this difference, the prediction of the analytical model is quite good, with the maximum base shear of each cycle and the corresponding roof displacement displaying acceptable agreement with the experimental data.

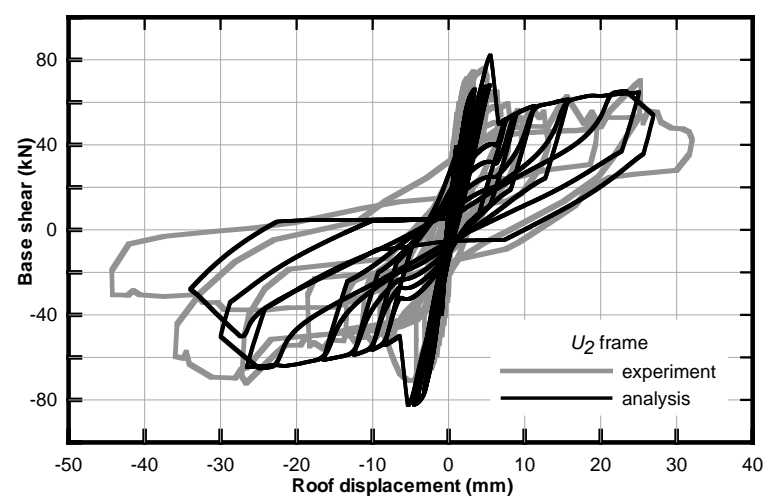

Fig. (28). $U_{3}$ frame: Comparison of experimentally and analytically derived load-displacement curves for cyclic loading $\left(f_{t}=953 \mathrm{MPa}\right.$ and $E_{1}=E_{2}=130000 \mathrm{MPa}$ ).

\subsection{Failure Modes Detection}

\subsubsection{Frame- $\mathrm{U}_{1}$}

The maximum lateral load recorded analytically for frame- $U_{l}$ was $12.52 \mathrm{kN}$ at $17.86 \mathrm{~mm}$ lateral displacement of the second floor, a value acceptable according to the experimentally recorded maximum load of $11.7 \mathrm{kN}$ at $17.8 \mathrm{~mm}$ displacement. As shown in Fig. (29b) the damage at the end of the analysis was concentrated at the first story which is in agreement with the final crack pattern from the experiment shown in Fig. (29a). Notice that sections with dark shade in Fig. (29b) denote yielding of the reinforcement.

\subsubsection{Frame- $\mathrm{U}_{2}$}

A difference is observed between the analytically derived maximum lateral load of $71.5 \mathrm{kN}$ at $2.97 \mathrm{~mm}$ roof displacement and the experimentally derived maximum load of 59.34 $\mathrm{kN}$ at $2.55 \mathrm{~mm}$ roof displacement. However, this difference

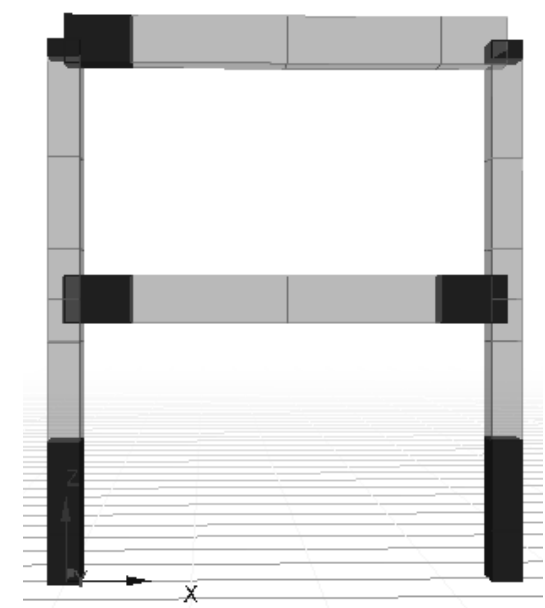

(b) Analytically derived failure mode. 


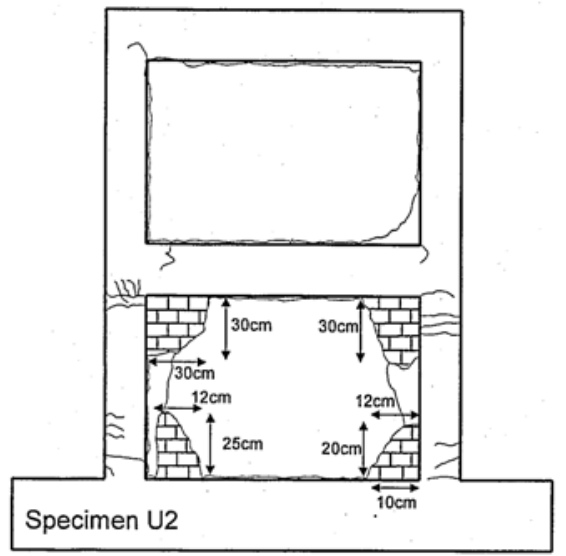

(a) Final crack pattern from the experiment - reproduced from [28].

Fig. (30). Failure modes for specimen $U_{2}$.

is smoothed out after a small number of loading cycles as shown in Fig. (25). The damage according to the test was accumulated at the first story and included sliding and crushing of the infill panel at the compression regions. After crushing the specimen started to deform appreciably more and the lateral load for fixed displacement dropped significantly [28]. This can be observed also by the analysis as shown in Fig. (25). After the formation of plastic hinges at the columns of the $1^{\text {st }}$ story because of deterioration of bond and crushing of the infill panel along the compression strut, drastic decrease of stiffness occurred after the $10^{\text {th }}$ cycle of loading. As shown in Fig. (30b) the failure mode according to the analysis includes damage at the $1^{\text {st }}$ story mostly, with plastic hinges formation at the top and bottom of the $1^{\text {st }}$ story columns which is in agreement with the test results for specimen $U_{2}$ as shown in Fig. (30a).

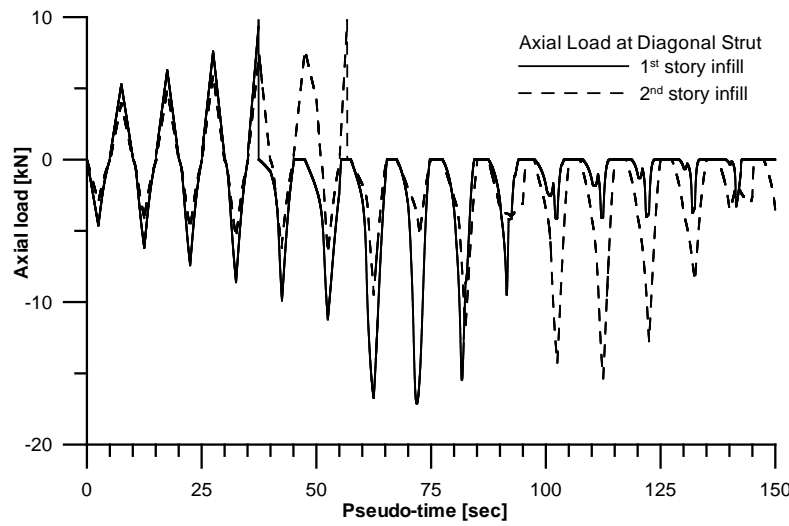

Fig. (31). Axial force acting at the diagonal strut that connects the internal node 4 with the dummy node 2 .

In Figs. (31) and (32) the axial forces acting along the compressive strut that connects the internal node 4 with the dummy node 2 and the shear forces acting on the corresponding shear spring, according to Fig. (6), for the infill panel of the $1^{\text {st }}$ and $2^{\text {nd }}$ story are depicted, respectively. It can be observed that, after the first few cycles the compressive strut of the $1^{\text {st }}$ story and $2^{\text {nd }}$ story, consecutively, does not react to tension, which denotes a separation of the infills from the corners or cracking of the masonry perpendicular to

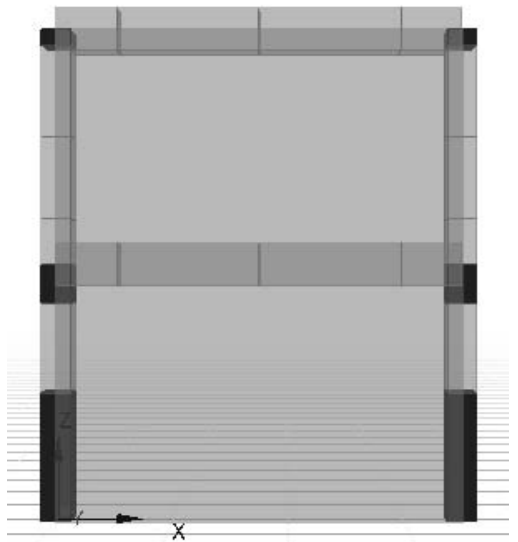

(b) Analytically derived failure mode.

the diagonal where tension is developed at each cycle. The axial loads developed at the $1^{\text {st }}$ story strut are greater than the $2^{\text {nd }}$ story, justifying the concentration of damage at the $1^{\text {st }}$ story. The $10^{\text {th }}$ loading cycle corresponds to pseudo-time of $100 \mathrm{sec}$. At that instance the axial load that can be developed along the compressive strut significantly decreases because of the decrease of the strut area at the value of $A_{2}$, resulting in a significant loss of lateral stiffness which agrees with the experimental results. The compressive force at the $2^{\text {nd }}$ story strut increases rapidly; however, without affecting the lateral stiffness, since the plastic hinges have already been developed in the $1^{\text {st }}$ story.

The shear forces that developed at the analysis are more pronounced for the $1^{\text {st }}$ story also, as shown in Fig. (32).

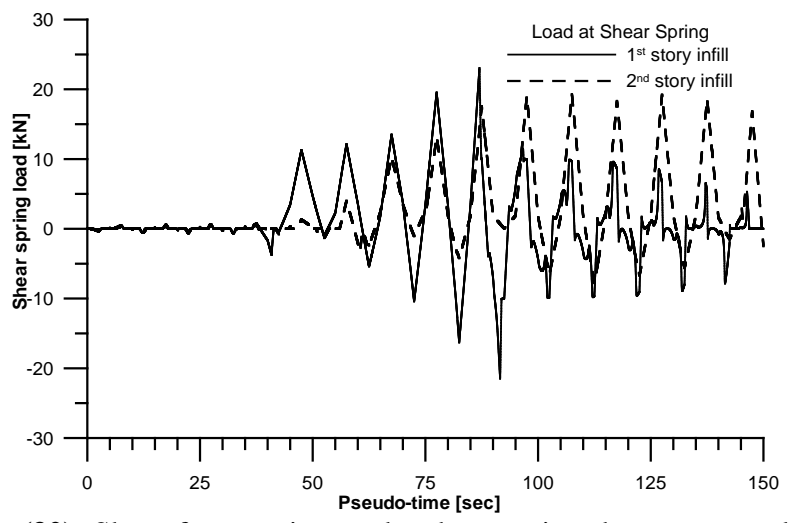

Fig. (32). Shear force acting at the shear spring that connects the internal node 4 with the internal node 2 .

\subsubsection{Frame- $\mathrm{U}_{3}$}

The maximum base shear for the retrofitted frame- $U_{3}$ was $74.61 \mathrm{kN}$ recorded at a roof displacement of $3.12 \mathrm{~mm}$ during the experiment [28]. The corresponding analytically derived maximum lateral load was $82.50 \mathrm{kN}$ developed at $3.80 \mathrm{~mm}$ roof displacement. The shape and the maximum values of the analytically derived shear curves, shown in Fig. (28), are acceptably accurate. However, some differences are observed in the failure modes. The failure of frame- $U_{3}$ includes [28]: 


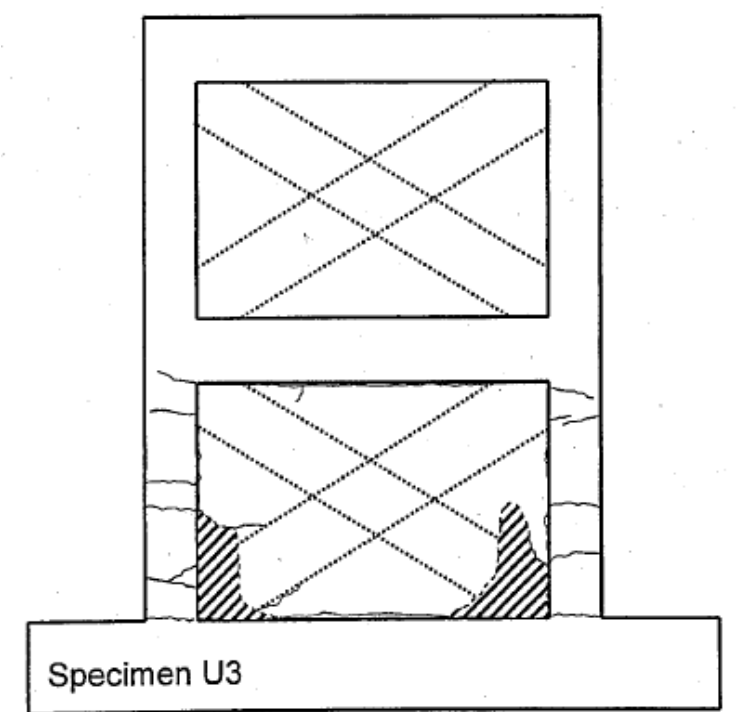

(a) Final crack pattern from the experiment - reproduced from [28].

Fig. (33). Failure modes for specimen $U_{3}$.

- Delaminating of CFRP overlay near the frame foundation and sliding between the beam and $1^{\text {st }}$ story infill at the $14^{\text {th }}$ loading cycle,

- Significant cracking at the corners of the tension struts, at the $15^{\text {th }}$ loading cycle,

- Fracture and debonding along CFRP cross overlay at foundation level at the $17^{\text {th }}$ loading cycle, and

- Failure of anchor dowels by pull-out cone at the foundation level and spalling of concrete to midheight of the $1^{\text {st }}$ story columns at the $18^{\text {th }}$ and $19^{\text {th }}$ loading cycle.

The final crack pattern is shown in Fig. (33a). This type of failures that are related to the anchorage and debonding of the CFRP is difficult to be modeled without the use of a more sophisticated analytical representation. As already mentioned in Section 3.4 the tensile strength $f_{t}$ of the FRP was determined based on the axial deformation at failure. As shown in Fig. (33b) a failure until midheight of the $1^{\text {st }}$ story columns can be expected by the analysis; however, a similar result regards the columns of the $2^{\text {nd }}$ story, a fact not observed at the experiment [28]. In the analysis the FRP retains a full contact with the frame and serves as a tension strut that transfers forces at the joint, intensifying the failure of the columns at the $2^{\text {nd }}$ story, while in the experiment the debonding of CFRP at the $1^{\text {st }}$ story was followed by a rapid failure of the anchors and increase of $1^{\text {st }}$ story drift. This rapid amplification of drifts because of debonding and anchor failure did not allow yielding of the $2^{\text {nd }}$ story columns of the experiment. Indeed the yielding of $2^{\text {nd }}$ story columns starts after the $14^{\text {th }}$ loading cycle, according to the analysis, when the anchorage failure begins.

Also yielding at the base of the $1^{\text {st }}$ story columns is developed at the $14^{\text {th }}$ and $15^{\text {th }}$ loading cycle in accordance with what was mentioned above for the experiment. A linear response has been detected for the $2^{\text {nd }}$ story FRP connectors according to the analysis, which agrees with the lack of observed damage at the FRP connectors at the $2^{\text {nd }}$ story, while

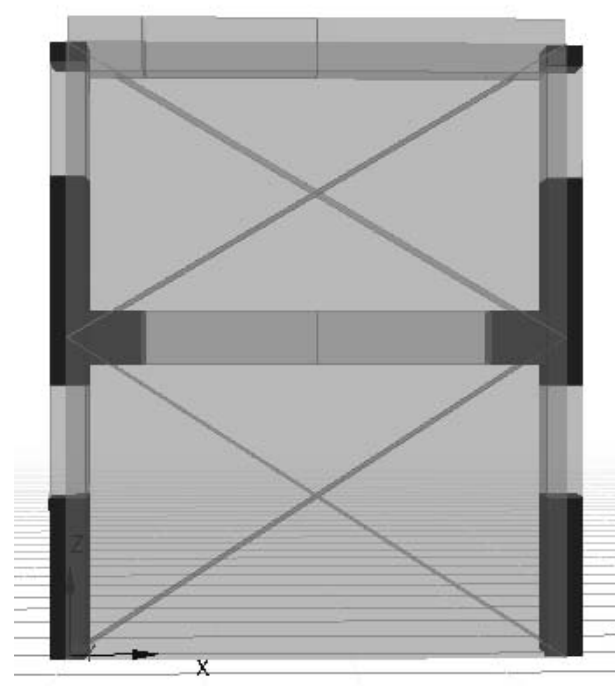

(b) Analytically derived failure mode.

the FRP connectors of the $1^{\text {st }}$ story reach their tensile strength at the $18^{\text {th }}$ loading cycle, as expected based on the selection of tensile strength for the FRP mentioned above. In Fig. (34) the hysteresis curves for the tensile force in the FRP connector of the $1^{\text {st }}$ and $2^{\text {nd }}$ story are shown. The failure modes of the analysis would have been closer to the experimental results in case there was provided an accurate anchoring of the CFRP sheets.

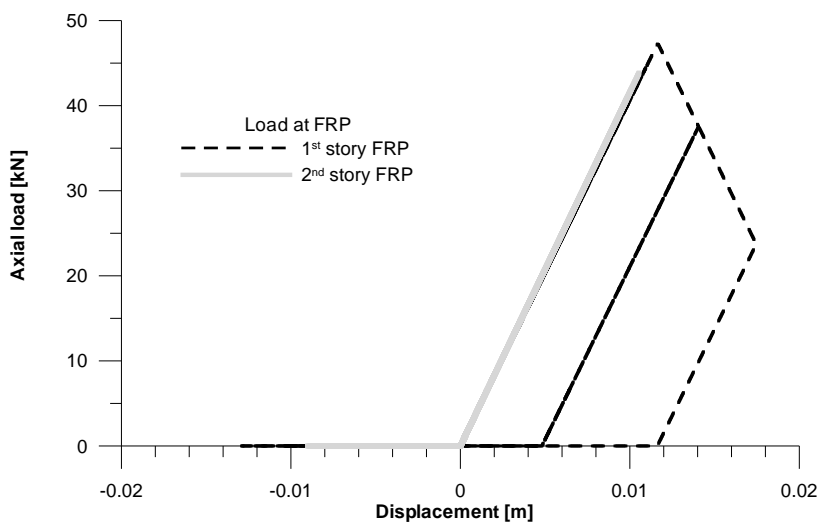

Fig. (34). Axial deformation - load curve for the FRP tension struts for frame- $U_{3}$.

The model proposed by Crisafulli has been developed to provide acceptably accurate results for the moments and shears of the surrounding RC members based on experimental data [9]. Satisfactory approximation of cycles leads to the conclusion that intensive loads of beams and columns will be accurately approximated, also. Nevertheless, lack of more data does not allow further investigation.

\subsection{Comparison of the Behaviour for the Three Frames}

In order to compare the difference in strength and stiffness characteristics of the three alternative frame models $U_{1}$, $U_{2}$ and $U_{3}$, the corresponding pushover curves are drawn in Fig. (35). It is reminded that $U_{1}$ corresponds to the bare 
frame, $U_{2}$ was the same frame with the addition of infill masonry walls and $U_{3}$ was similar to $U_{2}$ but the infill wall were strengthened with CFRP.

It is evident that the successive upgrading of the structure from the bare frame to a brick infilled masonry frame and to the addition of the FRP on the masonry, resulted in successive increase in the lateral resistance. The addition of the infill walls resulted in substantial increase in the stiffness, which was moderately affected by the addition of the FRP. Specifically, the maximum lateral resistance of frame $U_{1}$ was $13.75 \mathrm{kN}$, while the corresponding value for frame $U_{2}$ was $62.64 \mathrm{kN}$, demonstrating an increase of $355 \%$. In frame $U_{3}$, the strengthening with FRP lead to further increase in the resistance by $14 \%$, to a value of $71.55 \mathrm{kN}$. Concerning the stiffness, the initial elastic stiffness for frame $U_{1}$ was only $2.55 \mathrm{kN} / \mathrm{mm}$, while for frames $U_{2}$ and $U_{3}$ it was 63.53 $\mathrm{kN} / \mathrm{mm}$.

Significant difference was also observed in the displacement that corresponded to the maximum base shear: frame $U_{1}$ reached its maximum resistance when the roof displacement was $18.1 \mathrm{~mm}, U_{2}$ when it was $3.71 \mathrm{~mm}$ and $U_{3}$ when it was $4.26 \mathrm{~mm}$.

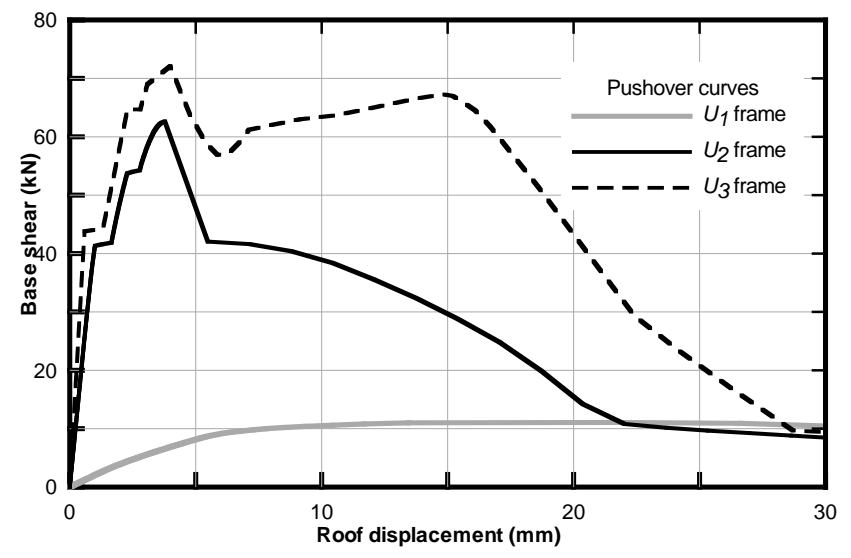

Fig. (35). Load-displacement pushover curves for frames $U_{1}, U_{2}$ and $U_{3}$.

The ductility capacity of the three frames was also significantly different. Frame $U_{1}$ showed that it could be deformed to large post-yield displacements, more than four times the yield displacement, without significant loss of strength. On the contrary, the behaviour of frame $U_{2}$ was characterized by a sharp drop of resistance after the maximum base shear was attained, evidently due to damage in the infill walls, showing a practically "brittle" response. However, the strengthening of the masonry with FRP in frame $U_{3}$ improved the response significantly, providing a relatively smooth maintenance of the resistance up to ductility around 4.0; for larger displacements, the resistance decreases sharply but remains always greater than that of $U_{2}$ without the FRP. It seems, therefore, that strengthening of the masonry with FRP improves significantly the response, as can also be seen comparing the cyclic response of frames $U_{2}$ and $U_{3}$ shown in Figs (25) and (28): the behaviour of $U_{3}$ was more stable and retained its resistance for a relatively large number of loops.

\section{DISCUSSION AND CONCLUSIONS}

The research presented in this paper aims to assess the effectiveness of CFRP strengthening of brick infilled RC frame structures, typical of past design concepts. Three types of two-storey, one-bay frames were analysed with models that were validated against experimental data available in the literature [25, 28]: (i) bare frame $U_{1}$; (ii) brick infilled frame $U_{2}$; and (iii) FRP strengthened brick infilled frame $U_{3}$. The calibration of the parameters of the models was performed using experimental data for specimens that were imposed to cyclic loading and was based on the comparison of the analytical with the experimental response for the same type of loading and additionally on the comparison of analytical pushover curves with backbone curves derived from the envelopes of the cyclic response of the test specimens. Although the pushover analysis can serve only as an initial approximation of the real inelastic behaviour, it was used for the accurate estimation of the elastic stiffness, the maximum lateral resistance and the corresponding displacement of the frames examined. In view of the present research the following conclusions can be drawn:

1. The analytical model for the masonry panel element developed by Crisafulli [9] could estimate effectively the response of the brick-infilled frames that were investigated experimentally. However, calibration of the critical parameters is needed, which, in the present study, was based on experimental results, not an easy task in engineering practice.

2. Comparisons of analytically derived pushover curves with backbone curves from cyclic tests can be used to calibrate the parameters of the numerical models. Caution should be paid to the use of this method on multistorey structures, where the results of the pushover analysis might diverge significantly from the dynamic response, being sensitive to several parameters including the pattern of the lateral load distribution and higher mode effects [44].

3. The role of the masonry walls on the response is significant since they increase the resistance and the stiffness. However, the overall behaviour is rather brittle, which justifies why for the seismic design masonry walls are not included in the assessment of the structural strength. The most critical parameters that affect the response of the masonry panel element were found to be the compressive strength $f_{\text {mas }}$, the modulus of elasticity $E_{\text {mas }}$ and the residual strut area strain $e_{2}$. Provided that these parameters are determined, as a minimum requirement, by either in-situ or laboratory testing, a more accurate assessment of the capacity of existing structures could be obtained. Considering the wide range of values for these parameters, insufficient knowledge will undoubtedly lead to unreliable assessment of the behavior. The standardization of values for some of these parameters based on the mechanical properties of the materials available today could help for a more rational design of new brickinfilled RC structures. This implies further analytical and experimental investigation; however, even when the exact mechanical properties are known, several factors may lead to unreliable prediction of the overall behavior of masonry if sufficient in-situ testing is not applied, i.e, 
poor construction detailing, role of openings and out-ofplane response. The default values selected for the most influential empirical parameters $\gamma_{u n}, \alpha_{c h}$ and $e_{x l}$ led to acceptable results regarding cyclic and monotonic response.

4. The effectiveness of the proposed retrofit scheme for brick infills was re-confirmed. Strengthening of masonry with FRP significantly increased the ductility capacity of the structure and improved its resistance. Therefore, this technique could be used to lessen the vulnerability of existing structures in earthquake-prone regions. The FRP retrofit has a major effect on the global resistance, since it does not considerably affect the stiffness and the mass of the structure, it does not modify the distribution of seismic loads from what was assumed in seismic design. The effectiveness of a relatively simple constitutive model for FRP in aproximating the real cyclic response allows for a realistic assessment of the behavior given that no debonding failure occurs, i.e., the appropriate anchorage is provided.

\section{CONFLICT OF INTEREST}

The authors confirm that this article content has no conflicts of interest.

\section{ACKNOWLEDGEMENTS}

The authors are most grateful to Umut Akgüzel who kindly provided the experimental results used in the present research. Also the valuable contribution of A. Kafkas and Ch. Klidis who performed preliminary parametric analyses is gratefully acknowledged.

\section{REFERENCES}

[1] EPANTYK, Seismic Strengthening of Existing Structures, Athens: Technical Chumber of Greece Editions, 2007. (in Greek)

[2] A. Kafkas, and C. Klidis, "Analytical Modelling of Experimental Results of Brick-Infilled Reinforced Concrete Frames With and Without Retrofit", Diploma thesis, School of Civil Engineering, National Technical University of Athens, Greece, 2010. (in Greek)

[3] Fédération Internationale du Béton (FIB), Retrofitting of Concrete Structures by Externally Bonded FRPs With Emphasis on Seismic Applications, Bulletin 35, Lausanne, Switzerland 2006.

[4] C.C. Spyrakos, Strengthening of Structures for Seismic Loads, Athens: Technical Chumber of Greece Editions, 2004. (in Greek)

[5] A.B. Mehrabi, P.B. Shing, M. Schuller, and J. Noland, "Experimental evaluation of masonry-infilled RC frames", ASCE J. Struct. Eng., vol. 122, no. 3, pp. 228-237, 1996.

[6] M. Tomaževič, Earthquake-Resistant Design Of Masonry Buildings, Imperial College Press: London, 1999.

[7] E. Vintzileou, and T.P. Tassios, "Seismic behaviour and design of infilled R.C. frames", Int. J. Earthquake Eng. Eng. Seismol., vol. 3, no. 2, pp. 22-28, 1989.

[8] B. Stafford-Smith, and C. Carter, "A method of analysis for infilled frames", Proc. Inst. Civil Eng., vol. 44, no. 1, pp. 31-48, 1969.

[9] F.J. Crisafulli, "Seismic Behaviour of Reinforced Concrete Structures with Masonry Infill", Ph. D. thesis, University of Canterbury, New Zealand, 1997.

[10] E. Smyrou, C.A. Blandon, S. Antoniou, R. Pinho, and H. Crowley, "Implementation and Verification of a Masonry Panel Model for Nonlinear Pseudo-Dynamic Analysis of Infilled RC Frames", In: Proceedings of the First European Conference on Earthquake Engineering and Seismology, Geneva, Switzerland, Paper no. 355, 2006.

[11] J.R. Riddington, and B. Stafford-Smith, "Analysis of infilled frames subject to racking with design recommendations", Struct. Eng., vol. 55, no. 6, pp. 263-268, 1977.

[12] A.B. Mehrabi, and P.B. Shing, "Finite element modelling of masonry-infilled RC frames", ASCE J. Struct. Eng., vol. 5, pp. 604613, 1997.
[13] P.G. Asteris, "Lateral stiffness of brick masonry infilled plane frames", ASCE J. Struct. Eng., vol. 129, no. 8, pp. 1071-1079, 2003.

[14] P.G. Asteris, "Finite element micro-modeling of infilled frames", Electron. J. Struct. Eng., vol. 8, pp. 1-11, 2008.

[15] A. Stavridis, and P.B. Shing, "Finite element modeling of nonlinear behavior of masonry-infilled RC frames", ASCE J. Struct. Eng., vol. 136, no. 3, pp. 285-296, 2009

[16] I. Koutromanos, A. Stavridis, P.B. Shing, and K. Willam, "Numerical modeling of masonry-infilled RC frames subjected to seismic loads", Comput. Struct., vol. 89, no. 11-12, pp.1026-1037, 2011.

[17] P.G. Asteris, S.T. Antoniou, D.S. Sophianopoulos, and C.Z. Chrysostomou, "Mathematical macromodeling of infilled frames: state of the art", ASCE J. Struct. Eng., vol. 137, no. 12, pp. 1-10, 2011.

[18] I.N. Doudoumis, "Finite element modelling and investigation of the behaviour of elastic infilled frames under monotonic loading", Eng. Struct., vol. 29, pp. 1004-1024, 2007.

[19] E. Smyrou, "Implementation and Verification of a Masonry Panel Model for Nonlinear Dynamic Analysis of Infilled RC Frames", M.Sc. Dissertation, European School for Advanced Studies in Reduction of Seismic Risk (ROSE School), Pavia, Italy 2006. [Online] Available; www.roseschool.it [Accessed Jan. 2012].

[20] D.J. Kakaletsis, and C.G. Karayannis, "Experimental investigation of infilled R/C frames with concentric openings", ACI Struct. J., vol. 106, no. 2, pp. 132-141, 2009.

[21] I. Erdem, U. Akyuz, U. Ersoy, and G. Ozcebe, "An experimental study on two different strengthening techniques for RC frames", Eng. Struct., vol. 28, no. 13, pp. 1843-1851, 2006.

[22] B. Binici, G. Ozcebe, and R.Ozcelik. "Analysis and design of FRP composites for seismic retrofit of infill walls in reinforced concrete frames", Compos., Part B, vol. 38, pp. 575-583, 2007.

[23] S. Altin, O. Anil, M.E. Kara, and M. Kaya, "An experimental study on strengthening of masonry infilled RC frames using diagonal CFRP strips", Compos., Part B, vol. 39, pp. 680-693, 2008.

[24] G. Ozcebe, U. Ersoy, T. Tankut, E. Erduran, R.S. Keskin, and H.C. Mertol, Strengthening of Brick-Infilled RC Frames With CFRP, Ankara: SERU - Structural Engineering Research Unit, TUBITAK - METU, 2003.

[25] S. Özden, and U. Akgüzel, "CFRP Overlays in Strengthening of Frames with Column Rebar Lap Splice Problem", In: Advances in Earthquake Engineering for Urban Risk Reduction, S.T. Wasti and G. Ozcebe, Eds. Springer: NATO Science Series, Earth and Environmental Sciences, vol. 66, pp. 455-471, 2006.

[26] L. Binda, and C. Tiraboschi, "Flat-Jack test as a slightly destructive technique for the diagnosis of brick and stone masonry structures", Int. J. Restor. Build. Monum., pp. 449-472, 1999.

[27] W.W. El-Dakhakhni, A.A. Hamid, Z.H.R. Hakam, and M. Elgaaly, "Hazard mitigation and strengthening of unreinforced masonry walls using composites", Compos. Struct., vol. 73, pp. 458-477, 2006.

[28] U. Akgüzel, "Seismic Retrofit of brick infilled R/C frames with lap splice problem in columns", M.Sc. thesis, Department of Civil Engineering, Bogazici University, Istanbul, Turkey, 2003.

[29] SeismoSoft, SeismoStruct v5.2.5 - A Computer Program for Static and Dynamic Nonlinear Analysis of Framed Structures, 2011. [Online] Available: http://www.seismosoft.com [Accessed Jan. 2012].

[30] A. Mari, and A. Scordelis, "Nonlinear Geometric Material and Time Dependent Analysis of Three Dimensional Reinforced and Prestressed Concrete Frames", SESM Report 82-12, Department of Civil Engineering, University of California, Berkeley, 1984.

[31] M. Menegotto, and P.E. Pinto, "Method of Analysis for Cyclically Loaded R.C. Plane Frames Including Changes in Geometry and Non-Elastic Behaviour of Elements Under Combined Normal Force and Bending", In: Symposium on the Resistance and Ultimate Deformability of Structures Acted on by Well Defined Repeated Loads, International Association for Bridge and Structural Engineering, Zurich, Switzerland, pp. 15-22, 1973.

[32] F.C. Filippou, E.P. Popov, and V.V. Bertero, "Modelling of R/C joints under cyclic excitations," ASCE J. Struct. Eng., vol. 109, no. 11, pp. 2666-2684, 1983.

[33] J.B. Mander, M.J.N. Priestley, and R. Park, "Theoretical stressstrain model for confined concrete," J. Struct. Eng., vol. 114, no. 8, pp. 1804-1826, 1988. 
[34] A. Prota, F. Cicco, and E. Cosenza, "Cyclic behavior of smooth steel reinforcing bars: Experimental analysis and modeling issues," J. Earthquake Eng., vol. 13, no. 4, pp. 500-519, 2009.

[35] J.E. Martinez-Rueda, and A.S. Elnashai, "Confined concrete model under cyclic load," Mater. Struct., vol. 30, no. 197, pp. 139-147, 1997.

[36] F.J. Crisafulli, and A.J. Carr, "Proposed macro-model for the analysis of infilled frame structures", Bull. N Z Soc. Earthquake Eng., vol. 40, no. 2, pp. 69-77, 2007.

[37] E. Smyrou, C. Blandon, S. Antoniou, R. Pinho, and F. Crisafulli, "Implementation and verification of a masonry panel model for nonlinear dynamic analysis of infilled RC frames", Bull. Earthquake Eng., vol. 9, no. 5, pp. 1519-1534, 2011.

[38] T. Paulay, and M.J.N. Priestley, Seismic Design of Reinforced Concrete and Masonry Buildings, John Wiley \& Sons Inc: New York, 1992.

[39] M. Holmes, "Steel frames with brickwork and concrete infilling," Proc. Inst. Civil Eng., vol. 19, pp. 473-478, 1961.
[40] B. Stafford-Smith, "Behaviour of Square Infilled Frames," Proc. ASCE, J. Struct. Div., vol. 92(ST1), pp. 381-403, 1966.

[41] C. Dymiotis, A.J. Kappos, and M.K. Chryssanthopoulos, "Seismic reliability of masonry-infilled RC frames", ASCE J. Struct. Eng., vol. 127, no. 3, pp. 296-305, 2001.

[42] I.E. Bal, H. Crowley, R. Pinho, and F.G. Gulay, "Detailed assessment of structural characteristics of turkish RC building stock for loss assessment models", Soil Dyn. Earthquake Eng., vol. 28, no. 10-11, pp. 914-932, 2008.

[43] G. Erol, E. Yuksel, H. Saruhan, G. Sagbas, P.T. Tuga, and H.F. Karadogan, "A Complementary Experimental Work on Brittle Partitioning Walls and Strengthening by Carbon Fibers", In: $13^{\text {th }}$ World Conference on Earthquake Engineering, Vancouver, B.C., Canada, Paper No. 979, 2004.

[44] S. Antoniou, and R. Pinho, "Displacement-Based Adaptive Pushover", In: Proceedings of Computational Methods in Structural Dynamics and Earthquake Engineering, COMPDYN 2009, CD, no. $448,2009$.

(C) Spyrakos et al.; Licensee Bentham Open.

This is an open access article licensed under the terms of the Creative Commons Attribution Non-Commercial License (http://creativecommons.org/licenses/by-nc/3.0/) which permits unrestricted, non-commercial use, distribution and reproduction in any medium, provided the work is properly cited. 